\title{
The Joint Dynamics of U.S. and Euro-area Inflation Rates: Expectations and Time- varying Uncertainty
}

\author{
Olesya Grishchenko ${ }^{1}$, Sarah Mouabbi ${ }^{2}$, Jean-Paul Renne ${ }^{3}$
}

\author{
Working Paper \# 622
}

February 2017

\section{ABSTRACT}

We use several U.S. and euro-area surveys of professional forecasters to estimate a dynamic factor model of inflation with time-varying uncertainty. We obtain survey-consistent distributions of future inflation at any horizon, both in the United States and in the euro area. Our methodology allows us to compute, in closed form, survey-consistent measures of inflation expectations, inflation uncertainty, inflation expectations anchoring, deflation probabilities and U.S. and euro-area inflation co-movements. Our results suggest strong commonalities between inflation dynamics in the two economies.

Keywords: inflation, surveys of professional forecasters, dynamic factor model with stochastic volatility, term structure of inflation expectations and inflation uncertainty, anchoring of inflation expectations.

JEL classification: C32, E31, E44.

\footnotetext{
${ }^{1}$ Federal Reserve Board, olesya.v.grishchenko@frb.gov

${ }^{2}$ Banque de France, Sarah.Mouabbi@banque-france.fr

${ }^{3}$ HEC Lausanne, Jean-Paul.Renne@unil.ch
} 


\section{NON-TECHNICAL SUMMARY ${ }^{4}$}

The Federal Reserve System (Fed) and the European Central Bank (ECB) are two of many central banks that have adopted a mandate for price stability devised to foster economic activity and employment. To meet this objective, both the Fed and the ECB pay close attention to various measures of inflation expectations implied both by financial market data and by surveys of professional forecasters. Surveys, in particular, have received considerable attention from policymakers and academic researchers. This notably reflects their documented success in forecasting inflation (e.g., Ang et al., 2007). Surveys are thus closely monitored and often mentioned in various monetary policy communications. Overall, regular references to survey-based measures of inflation expectations in various central banking communications reflect their importance for monetary policy decision-making process.

In this paper we exploit rich information contained in several surveys of professional forecasters with the goal of understanding the evolution of both inflation expectations and inflation uncertainty in the United States and in the euro area. Survey-based measures - unlike market-based measures of inflation expectations - are not affected by inflation risk premium, which may be considerable. In our model estimation, we rely both on survey-based consensus inflation forecasts that correspond to an average scenario and on probability distributions of future inflation rates that provide information about uncertainty surrounding this scenario. We propose a model that takes survey-based inflation forecasts (for various horizons and at varying frequencies) as inputs and produces survey-consistent distributions of inflation at any horizon.

We contribute to the literature of survey-based inflation expectations by constructing a model that takes survey-based inflation forecasts (for various horizons, at varying frequencies and with different definitions) as inputs and produces survey-consistent distributions of inflation at any horizon. Overall, the goal of the paper is not to forecast inflation, but rather construct comparable measures of inflation expectations and inflation uncertainty, for each area, respectively, that would be consistent with survey forecasts. Our model has several noteworthy features. First, common factors are allowed to drive the dynamics of inflation rates in both economies, reflecting ever-increasing interconnectedness between developed economies. Second, our model features time-varying

\footnotetext{
${ }^{4}$ We are grateful to Guido Ascari, Efrem Castelnuovo, Stefania D'Amico, Steven J. Davis, Darrell Duffie, Euler Pereira Goncalves de Mello, Luca Guerrieri, Refet Gurkaynak, Urban J. Jermann, Lutz Kilian, Nobuhiro Kiyotaki, Spencer Krane, Kajal Lahiri, David Lando, Hervé Le Bihan, Kevin Lee, Wolfgang Lemke, Tomasz Lyziak, Emanuel Moench, Phillipe Mueller, Stefan Nagel, Damjan Pfajfar, Patrick Pintus, Bruce Preston, Tatevik Sekhposyan, Hiroatsu Tanaka, Oreste Tristani, Jonathan Wright and Francesco Zanetti, as well as participants of the Inflation Targeting Seminar at the Central Bank of Brazil in May 2016, the 9th ECB workshop on inflation forecasting techniques in June 2016, 2016 annual conference of the International Association for Applied Econometrics, 2016 annual meeting of the Society for Financial Econometrics, 2016 Federal Reserve System's Committee on International Economic Analysis Conference, the 22nd international conference of the Society for Computational Economics, 2016 European Economic Association Meeting, 2016 Centre for International Research on Economic Tendency Surveys Conference, 2016 Melbourne Institute Macroeconomic Policy Meeting, the 2nd BdF-BoE International Macroeconomics Workshop and seminar participants at the European Central Bank and the Banque de France. We also thank Eric Horton for excellent research assistance provided for this project. Grishchenko is grateful to the Banque de France Research Foundation and University of Zurich for hospitality during her stays, when parts of the project have been accomplished. The views expressed in this paper are those of the authors and do not necessarily reflect the views of the Federal Reserve System or the Banque de France.
} 
inflation uncertainty. Third, our model is highly tractable because it offers closed-form solutions for conditional expectations and variances of future inflation rates at any horizon.

Our empirical results are as follows. First, our results highlight commonalities in inflation rates' dynamics of the United States and the euro area. For instance, estimated conditional correlations at one- and five-year horizons support the story of strong co-movement of inflation rates in the two economies. These correlations are relatively high, ranging between about 0.60 to 0.75 over our sample period. These findings suggest that common fundamental shocks appear to drive the economies in the United States and the euro area.

Second, we exploit our framework to assess how anchored inflation expectations are. In particular, we compute probabilities of future inflation rates falling in a certain range (e.g., between 1.5 and 2.5 percent or between 1.0 and 3.0 percent). Comparing these probabilities in the United States and the euro area, we find that, overall, longer-term inflation expectations in the euro area are more anchored than in the United States according to higher levels of these probabilities. However, the probability of five-year five years forward euro-area inflation being in the $[1.5 ; 2.5]$ percent range somewhat trended down from roughly 90 percent to just under 80 percent, while the probability of the U.S. inflation over a comparable horizon being in the same range increased notably since the financial crisis, from about 40 to roughly 70 percent, possibly reflecting explicit inflation targeting adopted by the Federal Reserve in January 2012.

Third, we compute probabilities of deflation in both areas and find that they are currently negligible despite some notable variation during the financial crisis, especially in the United States. We also find that the probability of inflation falling below 1 percent is currently non-negligible in Europe, where it is of around 40 percent for the one-year horizon, and just under 20 percent in the United States.

Euro area - Proba. that inflation in [1.5\%,2.5\%]

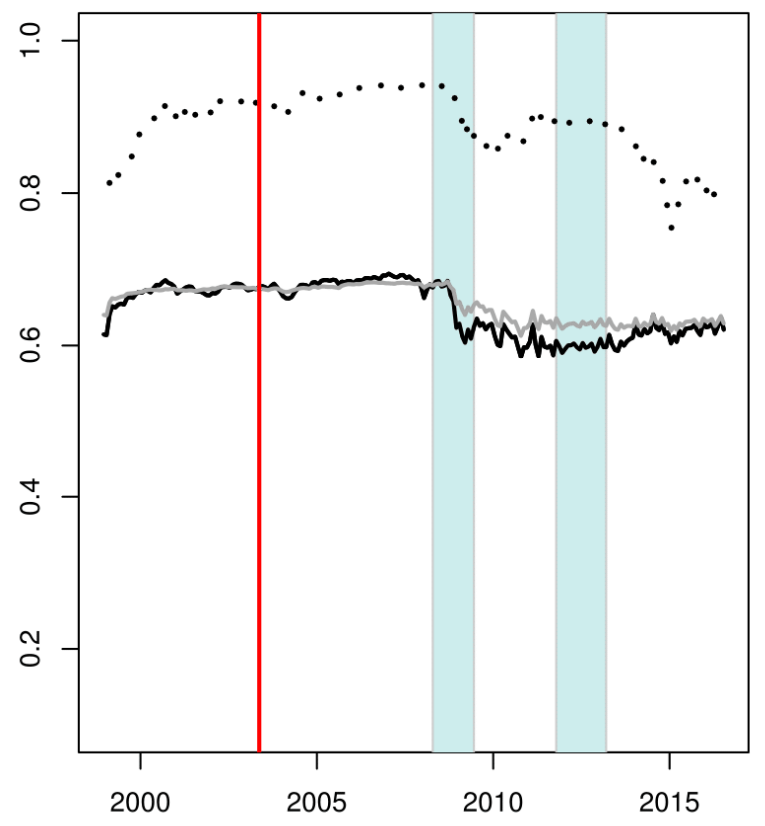

U.S. - Proba. that inflation in [1.5\%,2.5\%]

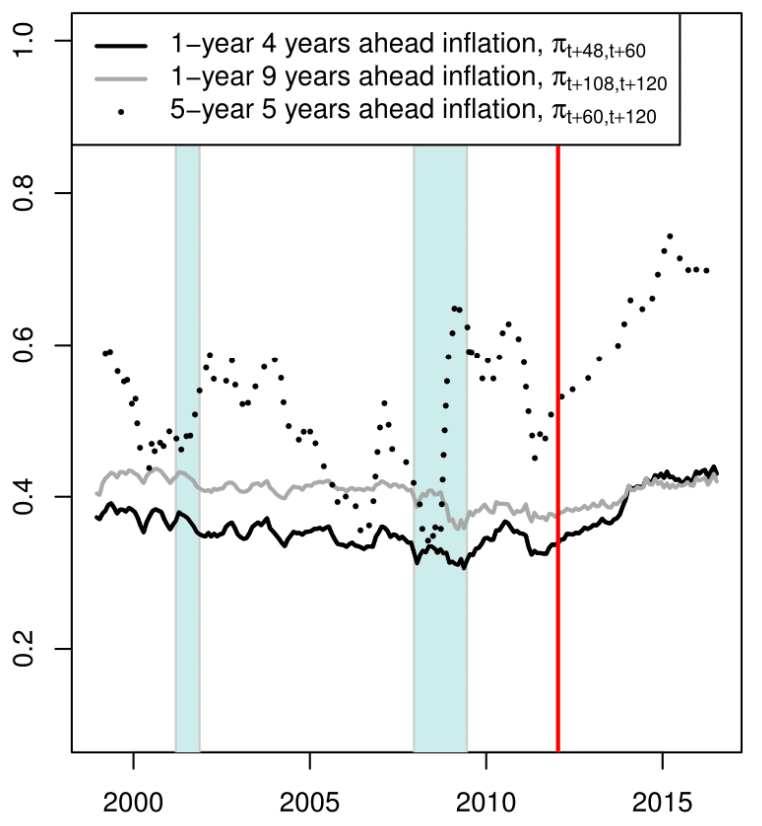




\section{RÉSUMÉ}

\section{LA DYNAMIQUE JOINTE DES TAUX D'INFLATION AUX ÉTATS-UNIS ET EN EUROPE :}

\section{ANTICIPATIONS ET INCERTITUDE VARIABLE DANS LE TEMPS}

Nous exploitons différentes enquêtes réalisées auprès de prévisionnistes professionnels pour estimer un modèle à facteurs et à volatilité stochastique de l'inflation. Nous en dérivons des distributions conditionnelles de l'inflation qui sont compatibles avec les données d'enquêtes utilisées lors de l'estimation du modèle. Ces distributions peuvent être calculées pour n'importe quel horizon, pour les États-Unis comme pour la zone euro. Notre méthodologie fournit des formules simples pour le calcul d'anticipations d'inflation, de mesures d'incertitude liée à l'inflation, de mesures d'ancrage des anticipations d'inflation, de probabilités de déflation et de mesures de co-mouvement entre les inflations américaines et européennes. Nos résultats mettent notamment en lumière l'importance des liens existant entre ces deux dernières.

Mots-clés : inflation, enquêtes de prévisionnistes professionnels, modèle à facteurs dynamiques et à volatilité stochastique, structure par terme des anticipations et de l'incertitude d'inflation, ancrage des anticipations d'inflation. 


\section{Introduction}

The Federal Reserve System (the Fed) and the European Central Bank (the ECB) are two of many central banks that have adopted a mandate for price stability devised to foster economic activity and employment. To meet this objective, both the Fed and the ECB pay close attention to various measures of inflation expectations implied both by financial market data and by surveys of professional forecasters. Surveys, in particular, have received considerable attention from policymakers and academic researchers. This notably reflects their documented success in forecasting inflation (e.g., Ang, Bekaert, and Wei, 2007). Surveys are thus closely monitored and often mentioned in various monetary policy communications. For instance, the Federal Open Market Committee (FOMC) minutes for the FOMC meeting of June 2016 state: "The Michigan survey measure of longer-run inflation expectations fell to its lowest level on record in early June, but other measures of such expectationsincluding those from the Survey of Professional Forecasters and from the Desk's Survey of Primary Dealers and Survey of Market Participants-were generally little changed, on balance, in recent months. ${ }^{11}$ Similarly, the accounts of monetary policy meeting of the ECB Governing Council of Octover 2016 state: "It was highlighted that survey-based measures of longer-term inflation expectations, such as the ECB's Survey of Professional Forecasters, were broadly unchanged for the period five years ahead, at around 1.8\%. However, while the average of point forecasts was stable, the Survey of Professional Forecasters also provided a probability distribution around the point forecasts which remained tilted to the downside. ${ }^{12}$ Overall, regular references to survey-based measures of inflation expectations in central banking communications reflect their importance for the monetary policy decision-making process.

In this paper we exploit rich information contained in several surveys of pro-

\footnotetext{
${ }^{1}$ See the FOMC minutes of June 14-15, 2016 at https://www.federalreserve.gov/ monetarypolicy/fomcminutes20160615.htm. In general, almost every release of the FOMC minutes refers to survey-based measures of inflation expectations, which clearly points out to the importance of these surveys.

${ }^{2}$ See the account of the ECB's Governing Council meeting on October 6, 2016, at https: //www. ecb. europa.eu/press/accounts/2016/html/mg161006.en.html.
} 
fessional forecasters with the goal of understanding the evolution of both inflation expectations and inflation uncertainty in the United States and in the euro area. Survey-based measures — unlike market-based measures of inflation expectations — are not affected by inflation risk premium, which may be considerable. ${ }^{3}$

We contribute to the literature of survey-based inflation expectations by constructing a model that takes survey-based inflation forecasts (for various horizons, at varying frequencies and with different definitions) as inputs and produces surveyconsistent distributions of inflation at any horizon. Overall, the goal of the paper is not to forecast inflation, but rather construct comparable measures of inflation expectations and inflation uncertainty, for each area, respectively, that would be consistent with survey forecasts. Our dynamic factor model has several noteworthy features. First, common latent factors are allowed to drive the dynamics of inflation rates in both economies, reflecting ever-increasing interconnectedness between developed economies (Monacelli and Sala, 2009; Ciccarelli and Mojon, 2010). Second, our model features stochastic volatility of inflation, hence allowing for time-varying inflation uncertainty. ${ }^{4}$ Third, our model is highly tractable because it offers closedform solutions for conditional first and second moments of future inflation rates at any horizon. This tractability is due to the fact that the factors in our econometric model follow so-called affine processes. The affine property of our factors implies that the model can be easily cast in the state-space form and subsequently estimated using Kalman filtering techniques. These techniques easily handle missing observations, which is particularly useful in our case, because different surveys are released at different points in time.

\footnotetext{
${ }^{3}$ Campbell and Viceira (2001), Buraschi and Jiltsov (2005) and Haubrich, Pennacchi, and Ritchken (2012) estimate the U.S. ten-year inflation risk premium to be 70,110 and 50 basis points, respectively; Ang, Bekaert, and Wei (2008) estimate the five-year inflation risk premium to be 114 basis points. Hördahl and Tristani (2010) estimate a joint model of the inflation risk premium in the United States and the euro area and find a positive inflation risk premium, which is increasing with the horizon.

${ }^{4}$ Engle (1982) was the first who emphasized time-varying inflation uncertainty in the context of an econometric model by specifying a new class of stochastic processes called autoregressive conditional heteroscedastic (ARCH) processes; Zarnowitz and Lambros (1987) were the first who emphasized time-varying inflation uncertainty in the context of the second moment of survey-based inflation distributions, the concept that we use in our model to proxy for inflation uncertainty.
} 
In our model estimation, we rely both on survey-based consensus inflation forecasts that correspond to an average scenario and on probability distributions of future inflation rates that provide information about uncertainty surrounding this scenario. ${ }^{5}$ We use this data to construct model-implied distributions at any horizon, from which inflation expectations (first conditional moment of the probability distribution) and inflation uncertainty (second conditional moment of the probability distribution) are drawn. Importantly, even though conditional moments reported in surveys are not based on the same inflation measure or do not coincide in terms of horizons, model-implied conditional distributions of inflation can be made perfectly comparable across the U.S. and euro-area economies. ${ }^{6}$

Our empirical results are as follows.

First, we find substantial commonalities in the dynamics of inflation rates of the United States and the euro area. In particular, out of four latent factors that drive the level of inflation rates in both economies in our model, one common factor appears to be important for the U.S. and euro-area economies and, out of two latent factors that drive conditional variances of inflation rates in both economies, one common factor appears to be the most important one for the variances of inflation rates. Our results support previous findings that inflation in industrialized countries is largely a global phenomenon. For example, Monacelli and Sala (2009) find that one international common factor explains between 15 and 30 percent of the variance in consumer prices in four OECD countries (United States, Germany, France and the United Kingdom), while Ciccarelli and Mojon (2010) find that inflation in 22 OECD countries have a common factor that accounts for nearly 70 percent of their variance. In addition, relatively high estimated model-implied conditional correlations at one- and five-year horizons (roughly ranging between 0.60 to 0.75 over our sample period of 1999-2016) support the argument of strong co-movements of infla-

\footnotetext{
${ }^{5}$ In our study, the surveys that provide point forecasts along with probability distributions do so at a forecaster level. However, so far, we abstract from considering disaggregated data.

${ }^{6}$ From one survey to another, respondents are asked to provide inflation forecasts based on different definitions (e.g., year-on-year growth rates of the price index, annualised growth rates over a given period, or averages of year-on-year growth rates).
} 
tion rates between our two global economies. The literature, so far, only focusses on the analysis of first-order moments — or point estimates — of future inflation rates across different economies. ${ }^{7}$ By contrast, our approach makes it possible to study their joint distribution and generates moments of inflation distributions that are adequately comparable across economies. For example, we find that conditional covariances of future inflation rates are related to Economic Policy Uncertainty (EPU) indices (Baker, Bloom, and Davis, 2016) and to the European Commission's and the University of Michigan's Economic Sentiment indices.

Second, model-implied moments of inflation distributions suggest two insights. First, our results are in line with other studies indicating that inflation expectations declined after 2010 in both economies, especially at short to intermediate horizons up to 5 years. $^{8}$ While it is straightforward to infer some inflation expectations from surveys, our measure is unique in a sense that it succinctly combines information from several relevant surveys and renders it comparable. The second insight regards inflation uncertainty — the second moment of inflation probability distributions drawn from surveys. We find that, compared to the euro area, inflation uncertainty has been higher in the United States over our entire sample period (1999-2016) and considerably higher in the first half of our sample. Higher U.S. inflation uncertainty may possibly reflect the fact that the Federal Reserve adopted an explicit inflation target only in January $2012 .{ }^{9}$ However, U.S. inflation uncertainty, at short and intermediate horizons, substantially declined in our sample, while euro-area inflation uncertainty somewhat increased at all considered horizons (up to 10 years). Interestingly, we find that longer-term inflation uncertainty also increased in our sample, despite the Fed's adoption of the inflation target. This finding is consistent with

\footnotetext{
${ }^{7}$ An exception includes the paper by Charemza, Díaz, and Makarova (2015), who use copula functions to estimate the uncertainty of Canadian inflation forecasts conditional on U.S. forecast uncertainty. Note that uncertainty here is defined as the forecast error of a time series econometric model.

${ }^{8}$ Measures of inflation compensation - the difference between nominal and TIPS yields of comparable maturities or inflation swaps - also point towards declining inflation expectations. However, these measures are affected by inflation risk premia and therefore, may not reflect inflation expectations accurately.

${ }^{9}$ See the press release at http://www.federalreserve.gov/newsevents/press/monetary/ 20120125 c.htm.
} 
Nagel (2016) who also finds higher inflation uncertainty at longer horizons in the United States, using market data.

Third, we contribute to a growing literature on the anchoring of inflation expectations (see, e.g., Bernanke, 2007; Gürkaynak, Levin, Marder, and Swanson, 2007; Beechey, Johannsen, and Levin, 2011; De Pooter, Robitaille, Walker, and Zdinak, 2014; Mehrotra and Yetman, 2014; Kumar, Afrouzi, Coibion, and Gorodnichenko, 2015; Nagel, 2016; Mertens, 2016; Buono and Formai, 2016; Łyziak and Paloviita, 2016; Speck, 2016). While different measures are used to define "anchored" expectations, most of them mainly reflect the stability of the conditional mean of inflation. ${ }^{10}$ However, the conditional mean (first-order moment) can be stable even if the conditional variance (second-order moment) is relatively high. Consider for instance the situation where the release of a given macroeconomic news results in a substantial increase in the long-term conditional variance (i.e. uncertainty) but has no effect on the conditional mean. That is, suppose we face equal increases in both downside and upside risks. In this situation, while long-term inflation expectations remain stable, the probability of having very high or very low future inflation rates increases substantially, which is at odds with a given concept of anchoring. We therefore propose a measure of "anchored" inflation expectations in terms of conditional distributions. Namely, we measure the extent to which inflation expectations are anchored in terms of probabilities of future inflation being in a certain range that is consistent with inflation targets in the United States or the euro area. As with other model-implied quantities, these probabilities can be computed for future inflation rates at any horizon. We find that, overall in our sample period, longer-term inflation expectations in the euro area are more anchored than in the United States given the higher level of these probabilities. However, the probability of five-year

\footnotetext{
${ }^{10}$ One popular measure of the anchoring of inflation expectations is the sensitivity of interest rates and inflation compensation measures to incoming macroeconomic news or shocks (see, e.g., Gürkaynak, Levin, Marder, and Swanson, 2007; Mishkin, 2007; Beechey, Johannsen, and Levin, 2011; De Pooter, Robitaille, Walker, and Zdinak, 2014). Other measures include the closeness of average beliefs to the central bank's inflation target, the dispersion of these beliefs across agents, confidence (i.e. relatively low uncertainty) in long-run beliefs of agents, revisions in forecasts and a co-movement between long-run and short-run inflation expectations (see, e.g., Kumar, Afrouzi, Coibion, and Gorodnichenko, 2015).
} 
five years forward euro-area inflation being in the [1.5;2.5]-percent range somewhat trended down from about 90 percent to just under 80 percent, while the probability of U.S. inflation being in the same range over the same horizon increased notably since the financial crisis, from about 40 to about 70 percent, possibly reflecting the adoption of the explicit inflation target by the Fed.

Fourth, we compute probabilities of deflation and low inflation outcomes for both economies. We find that (a) probabilities of deflation varied a lot during our sample period (ranging from roughly $0 \%$ to $10 \%$ for the euro area and $0 \%$ to $50 \%$ for the United States at the one-year horizon); (b) towards the end of our sample (mid-2016) probabilities of one-year ahead deflation are low in the euro area and negligible in the United States; and (c) in mid-2016 probabilities of one-year ahead inflation falling below 1 percent were around 10 and 40 percent in the United States and in the euro area, respectively. Other studies, such as Kitsul and Wright (2013) and Fleckenstein, Longstaff, and Lustig (2013) use inflation derivatives data to obtain these probabilities for the United States and find that market-based deflation probabilities at comparable near-term horizons in 2012-2013 are around 5 and 10 percent, respectively. For the same period and horizon, we obtain deflation probabilities of about $2 \%$. The difference between the two types of probabilities may correspond to deflation risk premiums, reflecting agents' aversion to deflation. ${ }^{11}$

In the remainder of the paper Section 2 provides a literature review, Section 3 introduces surveys, Section 4 describes our model and estimation strategy, Section 5 presents empirical results and Section 6 concludes. Appendix 7 gathers proofs, technical results and additional data descriptions.

\footnotetext{
${ }^{11}$ We define here the deflation risk premium as the difference between the probability of deflation under the risk-neutral (i.e. pricing) measure and the deflation probability under the physical measure. This specific risk premium is different from the inflation risk premium, also referred to as inflation term premium (Mishkin, 2007), which is the difference between the expectation of inflation under the risk-neutral measure (i.e. the inflation swap rates or the TIPS-based inflation compensation) and its expectation under the physical measure. As stated here, our results point to positive deflation risk premiums; we also obtain negative inflation risk premiums at the end of our sample.
} 


\section{Literature review}

Surveys became a popular tool in assessing expectations of inflation (and other macroeconomic variables). Growing empirical evidence suggests that surveys-based inflation forecasts outperform numerous statistical forecasting methods. For example, surveys appear (1) to outperform simple time-series benchmarks in forecasting inflation (Grant and Thomas, 1999; Thomas, 1999; Mehra, 2002); (2) to outperform other forecasting methods such as term structure models and the Phillips curve (Ang, Bekaert, and Wei, 2007; Chun, 2012); (3) to beat other forecasts in real time (as opposed to ex post revised data) (Faust and Wright, 2009; Croushore, 2010); and, finally, (4) to be consistent with inflation expectations embedded in Treasury yields (Chernov and Mueller, 2012). Faust and Wright (2013) provide a comprehensive overview of these inflation forecasting methods: they find that the Philadelphia Fed's Survey of Professional Forecasters, Blue Chip surveys and the Fed staff's Greenbook forecasts outperform numerous other methods.

As a result of this favourable attention, many researchers started using surveys as measures of inflation expectations (Roberts, 1995; Brissimis and Magginas, 2008; Bekaert and Engstrom, 2010; Del Negro and Eusepi, 2011; Grishchenko and Huang, 2013; Chun, 2014; Del Negro, Giannoni, and Schorfheide, 2015; Grishchenko, Vanden, and Zhang, 2016) and as inputs to constructing the term structure of inflation expectations (Chernov and Mueller, 2012; Aruoba, 2016). Several studies also incorporated inflation surveys in models aimed at capturing the joint dynamics of nominal and real yield curves (Chernov and Mueller, 2012; Haubrich, Pennacchi, and Ritchken, 2012; Piazzesi, Salomao, and Schneider, 2015; D’Amico, Kim, and Wei, 2016). ${ }^{12}$

Despite the fact that surveys were extensively used to extract consensus infla-

\footnotetext{
${ }^{12}$ Surveys are included in the estimation of the term structure mainly for two (somewhat connected) reasons: (1) to overcome the small-sample problems related to the highly persistent nature of interest rates and to estimate more precisely parameters related to the physical drift of the state variables (see, e.g., Kim and Orphanides (2012) who use survey data on short-term interest rates to address this issue); (2) to better estimate the physical expectation of inflation that is reflected in survey forecasts.
} 
tion forecasts, survey-based inflation uncertainty measures only recently attracted attention for two reasons: (1) inflation uncertainty appears to be time-varying (e.g., Zarnowitz and Lambros, 1987) and (2) it seems to be an important risk factor in determining the nominal bond risk premium (Buraschi and Jiltsov, 2005; Piazzesi and Shneider, 2007; Rudebusch and Swanson, 2008; Campbell, Sunderam, and Viceira, 2013). It is hence important to measure this risk accurately. Surveys appear to be a natural data set to measure inflation uncertainty but few surveys contain inflation probability distribution functions. ${ }^{13}$ Therefore, disagreement over point inflation forecasts often serves as a proxy for uncertainty because the two measures are known to be closely correlated (Zarnowitz and Lambros, 1987; Giordani and Soderlind, 2003; Wright, 2011). Recent literature has further studied disagreement and/or uncertainty survey measures (Lahiri and Sheng, 2010; Conflitti, 2011; Rich, Song, and Tracy, 2012; Andrade and Le Bihan, 2013; Boero, Smith, and Wallis, 2014; D'Amico and Orphanides, 2014). In our paper, applying the law of total variance, we define our uncertainty measure as the sum of disagreement and the average of forecasters' perceived uncertainty.

A natural extension of term structure models wtih inflation expectations is a model where both first and second moments of inflation are time-varying. Stock and Watson (2007) propose such a model without, however, investigating its term structure implications. By contrast, Haubrich, Pennacchi, and Ritchken (2012) and Fleckenstein, Longstaff, and Lustig (2013) exploit stochastic volatility models of inflation to derive conditional moments of inflation. While Fleckenstein, Longstaff, and Lustig (2013) only use market data to estimate their model, Haubrich, Pennacchi, and Ritchken (2012) use both market and survey data. ${ }^{14}$ In the latter paper, however, authors only use conditional first-order moments and do not involve second-order moments of survey inflation distributions.

\footnotetext{
${ }^{13}$ See sections 7.4 .1 and 7.4 .2 for details.

${ }^{14}$ Kitsul and Wright (2013) also use market (inflation derivatives) data to compute a relatively "model-free" inflation density and study the effect of macroeconomic announcements on the inflation density, but they do not use a stochastic volatility model to fit the data.
} 


\section{Survey data}

In our model estimation, we use several surveys of professional forecasters for the United States and for the euro area. We obtain inflation forecast data from the following surveys: the Survey of Professional Forecasters conducted by the Federal Reserve Bank of Philadelphia (US-SPF), the Survey of Primary Dealers conducted by the Federal Reserve Bank of New York (SPD), the Blue Chip Survey of Financial Forecasts and Economic Indicators (Blue Chip, or BCFF and BCEI hereafter), the Survey of Professional Forecasters conducted by the European Central Bank (ECB-SPF) and the Consensus Economics Survey (CES). Our sample period is from January 1999 (the onset of the euro area and the start date of the ECB SPF) to June 2016.

We construct a detailed database of inflation expectation surveys at various horizons for the above surveys. Several issues need to be accounted for when surveys are used in the estimation of our model. First, different surveys use different definitions of inflation. ${ }^{15}$ Second, different surveys provide inflation forecasts for different horizons. Third, surveys differ in frequency of their availability (quarterly, FOMC, and monthly frequencies). Finally, surveys typically provide point estimates but may also provide information on the distribution of inflation as well as individual forecasters' estimates. ${ }^{16}$ Table 1 summarizes the forecast variables extracted from different surveys and Sections 7.4.1 and 7.4.2 provide specific details about the surveys.

\section{[Insert Table 1 about here.]}

\footnotetext{
${ }^{15}$ Specifically, there are three different definitions of inflation in the various surveys used and we account for all three in our model estimation.

${ }^{16}$ Our model assumes the existence of a representative forecaster. Hence, it does not account for the heterogeneity associated with the availability of individual estimates. Accordingly, in our estimation, we use the average of survey outputs (i.e. point estimates and/or distributions).
} 


\section{Model and estimation strategy}

\subsection{Inflation and its driving factors}

Let us denote by $\pi_{t, t+h}^{(i)}$ the annualized inflation rate in economy $i$ between dates $t$ and dates $t+h$, defined as the log difference in the price index $P_{t}^{(i)}$ :

$$
\pi_{t, t+h}^{(i)}=\frac{12}{h} \log \left(\frac{P_{t+h}^{(i)}}{P_{t}^{(i)}}\right) .
$$

We assume that the annual inflation rate, $\pi_{t-12, t}^{(i)}$, is a linear combination of factors gathered in the $n \times 1$ vector $Y_{t}=\left(Y_{1, t}, \ldots, Y_{n, t}\right)^{\prime}$. As specified below, the dynamics of $Y_{t}$ is such that the marginal mean of $Y_{t}$ is zero. Importantly, $Y_{j, t}$ factors, where $j \in\{1, \ldots, n\}$, may be common to different economies:

$$
\pi_{t-12, t}^{(i)}=\bar{\pi}^{(i)}+\delta^{(i)^{\prime}} Y_{t}
$$

We assume that the distribution of $Y_{t}$ is Gaussian conditional on its past realization $\underline{Y_{t-1}}=\left\{Y_{t-1}, Y_{t-2}, \ldots\right\}$ and another $q \times 1$ exogenous vector $z_{t}=\left(z_{1, t}, \ldots, z_{q, t}\right)^{\prime}$ that affects the variance of $Y_{t}$. Specifically, $Y_{t}$ is given by:

$$
Y_{t}=\Phi_{Y} Y_{t-1}+\Theta\left(z_{t}-\bar{z}\right)+\operatorname{diag}\left(\sqrt{\Gamma_{Y, 0}+\Gamma_{Y, 1}^{\prime} z_{t}}\right) \varepsilon_{Y, t}, \quad \varepsilon_{Y, t} \sim \mathcal{N}(0, I)
$$

where $\bar{z}$ is the unconditional mean of $z_{t}, \Gamma_{Y, 0}$ is an $n \times 1$ vector and $\Gamma_{Y, 1}$ is a $q \times n$ matrix. According to (3) $z_{t}$ affects both the conditional expectation and variance of $Y_{t}{ }^{17}$ Vector $z_{t}$ is essential for modelling time-varying inflation variances so we refer to $z_{t}$ as the uncertainty vector (and to $z_{j, t}$ as the uncertainty factors) hereinafter.

The specification of the conditional variance in (3) implies that the entries of $\Gamma_{Y, 0}+\Gamma_{Y, 1}^{\prime} z_{t}$ have to be non-negative for all $t$. To achieve this, we assume that all elements of $\Gamma_{Y}$ vectors are non-negative and that $z_{t}$ follows a multivariate auto-

\footnotetext{
${ }^{17}$ Using volatility factors in the specification of the conditional expectation of inflation is for instance considered in Caporale, Onorante, and Paesani (2012) and Andrade, Fourel, Ghysels, and Idier (2014). It is notably consistent with the findings of Capistrán and Timmermann (2009) (Table 3).
} 
regressive gamma process. As shown in Appendix 7.2, the dynamics of $z_{t}$ admits the following weak VAR representation:

$$
z_{t}=\mu_{z}+\Phi_{z} z_{t-1}+\operatorname{diag}\left(\sqrt{\Gamma_{z, 0}+\Gamma_{z, 1}^{\prime} z_{t-1}}\right) \varepsilon_{z, t}
$$

where, conditional on $\underline{z_{t-1}}, \varepsilon_{z, t}$ has a zero mean and a unit diagonal covariance matrix and where $\Gamma_{z, 0}$ is a $q \times 1$ vector and $\Gamma_{z, 1}$ is a $q \times q$ matrix.

Given the dynamics of $Y_{t}$ and $z_{t}$, the VAR form of the dynamics followed by $X_{t}=\left(Y_{t}^{\prime}, z_{t}^{\prime}\right)^{\prime}$ is:

$$
X_{t}=\left[\begin{array}{c}
Y_{t} \\
z_{t}
\end{array}\right]=\mu_{X}+\Phi_{X}\left[\begin{array}{c}
Y_{t-1} \\
z_{t-1}
\end{array}\right]+\Sigma_{X}\left(z_{t-1}\right) \varepsilon_{X, t}
$$

where $\varepsilon_{X, t}$ is a $(n+q)$-dimensional unit-variance martingale difference sequence and where:

$$
\begin{aligned}
& \mu_{X}=\left[\begin{array}{c}
-\Theta \Phi_{z}\left(I-\Phi_{z}\right)^{-1} \mu_{z} \\
\mu_{z}
\end{array}\right], \quad \Phi_{X}=\left[\begin{array}{cc}
\Phi_{Y} & \Theta \Phi_{z} \\
0 & \Phi_{z}
\end{array}\right], \\
& \Sigma_{X}\left(z_{t-1}\right) \Sigma_{X}\left(z_{t-1}\right)^{\prime}=\left[\begin{array}{cc}
\Sigma_{11} & \Sigma_{12} \\
\Sigma_{12}^{\prime} & \Sigma_{22}
\end{array}\right], \\
& \operatorname{with}\left\{\begin{array}{l}
\Sigma_{11}=\Theta \times \operatorname{diag}\left(\Gamma_{z, 0}+\Gamma_{z, 1}^{\prime} z_{t-1}\right) \times \Theta^{\prime}+\operatorname{diag}\left(\Gamma_{Y, 0}+\Gamma_{Y, 1}^{\prime}\left(\mu_{z}+\Phi_{z} z_{t-1}\right)\right), \\
\Sigma_{22}=\operatorname{diag}\left(\Gamma_{z, 0}+\Gamma_{z, 1}^{\prime} z_{t-1}\right), \\
\Sigma_{12}=\Theta \Sigma_{22} .
\end{array}\right.
\end{aligned}
$$

An important property of $X_{t}$ is that it is affine (see Appendix 7.1.1). This implies that, conditionally on $\underline{X_{t}}=\left\{X_{t}, X_{t-1}, \ldots\right\}$, the first and second conditional moments of any linear combination of future values of $X_{t}$ are affine functions of $X_{t}$. In particular, since the realized log annual growth rate of the price index $\pi_{t-12, t}^{(i)}$ is an affine transformation of $X_{t}$ (see eq. (2)), its first and second moments can be 
written as affine functions of the $X_{t}$ factors as well:

$$
\begin{aligned}
\mathbb{E}_{t}\left(\pi_{t+h-12, t+h}^{(i)}\right) & =\bar{\pi}^{(i)}+a_{h}^{(i)}+b_{h}^{(i)^{\prime}} X_{t} \\
\operatorname{Var}_{t}\left(\pi_{t+h-12, t+h}^{(i)}\right) & =\alpha_{h}^{(i)}+\beta_{h}^{(i)^{\prime}} X_{t}
\end{aligned}
$$

where $\mathbb{E}_{t}(\bullet)$ and $\operatorname{Var}_{t}(\bullet)$ respectively denote the expectations and variances conditional on $\underline{X_{t}}$. In our empirical analysis we consider inflation forecast rates over different horizons because of the nature of the surveys we fit. In particular, we calculate the annualized $h$-period ahead inflation rates $\pi_{t, t+h}^{(i)}=(12 / h) \log \left(P_{t+h}^{(i)} / P_{t}^{(i)}\right)$, which are also affine functions of $Y_{t}$ and hence of $X_{t}$ :

$$
\pi_{t, t+h}^{(i)}=\bar{\pi}^{(i)}+\frac{1}{k} \delta^{(i)^{\prime}}\left(Y_{t+12}+Y_{t+24}+\cdots+Y_{t+h}\right)
$$

where $h=12 \times k$. Therefore, their first and second moments can be also written as affine functions of $X_{t}$ :

$$
\begin{aligned}
\mathbb{E}_{t}\left(\pi_{t, t+h}^{(i)}\right) & =\bar{\pi}^{(i)}+\bar{a}_{h}^{(i)}+\bar{b}_{h}^{(i)^{\prime}} X_{t} \\
\operatorname{Var}_{t}\left(\pi_{t, t+h}^{(i)}\right) & =\bar{\alpha}_{h}^{(i)}+\bar{\beta}_{h}^{(i)^{\prime}} X_{t} .
\end{aligned}
$$

Appendices 7.1.2 and 7.1.3 outline the recursive algorithms used to compute the parameters of the moments of the realized $\left(a_{h}^{(i)}, \alpha_{h}^{(i)}, b_{h}^{(i)}, \beta_{h}^{(i)}\right)$ and forecast $\left(\bar{a}_{h}^{(i)}\right.$, $\left.\bar{\alpha}_{h}^{(i)}, \bar{b}_{h}^{(i)}, \bar{\beta}_{h}^{(i)}\right)$ inflation rates. ${ }^{18}$

\subsection{State-space model and Kalman-filter estimation}

\subsubsection{Objective and strategy}

In addition to model parameters, we have to estimate the factors $X_{t}$ that are not observed by the econometrician. We handle both estimations in a joint manner

${ }^{18} a_{h}^{(i)}, \alpha_{h}^{(i)}, b_{h}^{(i)}$ and $\beta_{h}^{(i)}$ are obtained by setting $\gamma_{1}=\cdots=\gamma_{h-1}=\mathbf{0}$ and $\gamma_{h}=\left[\delta^{(i)^{\prime}}, \mathbf{0}\right]^{\prime}$ and $\bar{a}_{h}^{(i)}, \bar{\alpha}_{h}^{(i)}, \bar{b}_{h}^{(i)}$ and $\bar{\beta}_{h}^{(i)}$ are obtained by setting $\gamma_{1}=\cdots=\gamma_{11}=\gamma_{13}=\cdots=\gamma_{12 k-1}=\mathbf{0}$ and $\gamma_{12}=\gamma_{24}=\cdots=\gamma_{h}=\left[\delta^{(i)^{\prime}}, \mathbf{0}\right]^{\prime}$ in the recursive equations (16) and (17). 
using Kalman filtering techniques. The affine property of the process $X_{t}$ is key to the tractability of the estimation. Specifically, we not only do have closed-form formulas for conditional expectations and variances (9) and (10), but they also are affine, allowing us to cast the model into the linear state-space form, which is the required form of the model for the Kalman filter algorithm. This is a fundamental difference between our approach and alternative inflation models exhibiting stochastic volatility (see, e.g., Stock and Watson, 2007; Mertens, 2016). Indeed, while the latter models entail closed-form expressions for the first two conditional moments of inflation, the second-order moments are non-linear in the unobserved factors, which substantially complicates the model estimation.

A state-space model consists of two types of equations: transition equations and measurement equations. Transition equations describe the dynamics of the latent factors, as in eq. (5). Measurement equations specify the relationship between the observed variables and the latent factors. A by-product of the Kalman filter algorithm is the likelihood function. Parameter estimates can therefore be obtained by maximising this function.

\subsubsection{Measurement equations}

The state-space model involves three types of measurement equations:

(a) The first set of equations states that, for each economy $i$, the realised inflation rate is equal to linear combination of factors $Y_{t}$, as stated by eq. (2), with area-specific loadings.

(b) The second set of equations states that, up to the measurement error, surveybased expectations of future inflation rates are equal to the model-implied ones, that is:

$$
S P F_{t}=\overline{\boldsymbol{\pi}}+\mathbf{a}+\mathbf{b}^{\prime} X_{t}+\operatorname{diag}\left(\sigma^{a v g}\right) \eta_{t}^{a v g}
$$

where $\eta_{t}^{a v g}$ is a vector of iid Gaussian measurement errors, $S P F_{t}$ gathers all survey-based inflation expectations available at date $t$ and the entries of vector 
$\overline{\boldsymbol{\pi}}$, the vector $\mathbf{a}$ and the matrix $\mathbf{b}$ are based on the appropriate $\bar{\pi}^{(i)} \mathrm{s}, a_{h}^{(i)} \mathrm{s}, b_{h}^{(i)} \mathrm{s}$, $\bar{a}_{h}^{(i)}$ s and $\bar{b}_{h}^{(i)}$ s (see eqs. (6) and (9)).

(c) The third set of equations states that, up to the measurement error, surveybased variances are equal to the model-implied ones, i.e.:

$$
V S P F_{t}=\boldsymbol{\alpha}+\boldsymbol{\beta}^{\prime} X_{t}+\operatorname{diag}\left(\sigma^{v a r}\right) \eta_{t}^{v a r}
$$

where $\eta_{t}^{v a r}$ is a vector of iid Gaussian measurement errors, VSPF gathers all survey-based conditional variances of inflation forecasts available at date $t$, and the entries of the vector $\boldsymbol{\alpha}$ and the matrix $\boldsymbol{\beta}$ are based on the appropriate $\alpha_{h}^{(i)} \mathrm{s}, \beta_{h}^{(i)} \mathrm{s}, \bar{\alpha}_{h}^{(i)} \mathrm{s}$ and $\bar{\beta}_{h}^{(i)} \mathrm{s}$ (see eqs. (7) and (10)).

Let us denote by $S_{t}$ the vector of observations used in the state-space model. Since the latter is based on equations of types (a), (b) and (c), we have $S_{t}=$ $\left[\pi_{t}^{(1)}, \pi_{t}^{(2)}, S P F_{t}^{\prime}, V S P F_{t}^{\prime}\right]^{\prime}$. Using obvious notations, the measurement equations of the state-space model read:

$$
S_{t}=A+B^{\prime} X_{t}+\operatorname{diag}\left(\sigma^{S}\right) \eta_{t}^{S}
$$

where $\operatorname{Var}\left(\eta_{t}^{S}\right)=I d$.

\subsubsection{Discussion of model estimation}

At this stage, four remarks are in order. First, most survey forecasts are not released every month (with the exception of Blue Chip surveys), so $S P F_{t}$ and $V S P F_{t}$ variables are not available every month and thus their series contain missing observations when measured at a monthly frequency. ${ }^{19}$ Fortunately, it is straightforward to adjust the Kalman filter in order to handle missing observations (for details see Harvey and Pierse, 1984; Harvey, 1989). For the months when no $S P F_{t}$ and $V S P F_{t}$

\footnotetext{
${ }^{19}$ An alternative, but equivalent, view would be that the vectors and matrices $\overline{\boldsymbol{\pi}}, \mathbf{a}, \mathbf{b}, \boldsymbol{\alpha}$ and $\boldsymbol{\beta}$ have time-varying sizes.
} 
variables are available, the filter is still able to produce estimates of all latent factors, though with lower precision.

The second remark is about the Kalman filter performance in our case. While the affine form of our transition and measurement equations facilitates the implementation of the filter, the filter we eventually run is not optimal. It would have been optimal had the conditional covariance matrix $\Sigma_{X} \Sigma_{X}^{\prime}$ in eq. (5) not been dependent on $X_{t-1}$. However, this is not the case given some entries of $\Gamma_{Y, 1}$ are non-null. ${ }^{20}$ Therefore, we estimate our model using a quasi-maximum-likelihood (QML) approach (see, e.g., Duan and Simonato, 1999; de Jong, 2000).

The third remark is about the number of factors used in our subsequent empirical analysis. In our model two types of factors are used, namely, level and uncertainty factors. We consider a principal component analysis as a method to reduce the dimensionality of our data. The use of survey data comes with the difficulty of having to deal with many missing observations. To avoid such complications, we choose to proxy information on the level and uncertainty of inflation expectations using market-based data (i.e. inflation swaps and market-based variances), which are available at a higher frequency. ${ }^{21}$ Let us first determine the number of level factors. In our estimation approach, we impose a perfect fit of the two realised inflation rates; this amounts to "consuming" two factors. Accordingly, we first regress euroarea inflation swaps on euro-area realised inflation and U.S. inflation swaps on U.S. realised inflation. The residuals of these bivariate regressions are collected and a

\footnotetext{
${ }^{20}$ Our filter algorithm makes use of the standard forecasting and updating steps of the Kalman filter except that, at iteration $t$, we replace the unobserved covariance matrix of the $X_{t}$ innovations $\left(\Sigma_{X}\left(z_{t-1}\right) \Sigma_{X}\left(z_{t-1}\right)^{\prime}\right)$ by $\Sigma_{X}\left(z_{t-1 \mid t-1}\right) \Sigma_{X}\left(z_{t-1 \mid t-1}\right)^{\prime}$, where $z_{t-1 \mid t-1}$ denotes our filtered estimate of $z_{t-1}$ (using the information up to date $t-1$ ). Another adjustment we have to make to the filter pertains to the fact that factors $z_{t}$ are non-negative. For this purpose, after each updating step of the algorithm, negative entries in the $z_{t}$ estimate are replaced by 0 . Monte Carlo analyses run by Duan and Simonato (1999), Zhou (2001) and Monfort, Pegoraro, Renne, and Roussellet (2017) suggest that in the case of linear but heteroscedastic models, that kind of approximation may be of limited importance in practice (see also Duffee and Stanton (2012)).

${ }^{21}$ In most studies that model inflation swaps (or breakeven inflation rates — nominal yields minus real yields of comparable maturities), both inflation expectations and swaps are linear combinations of latent factors. In this setting, the number of factors driving inflation expectations coincides with those driving inflation swaps (Chernov and Mueller, 2012; Haubrich, Pennacchi, and Ritchken, 2012; Piazzesi, Salomao, and Schneider, 2015; D'Amico, Kim, and Wei, 2016). By extension, the same principle can be applied for variances. For further details on market-based data, refer to Appendix 7.6.
} 
principal component analysis is conducted on them. Panel A of Table 2 displays the results of this analysis, which indicate that the two first components explain about $93 \%$ of the cross-sectional variation observed. We now proceed in regressing every inflation swap on the realised inflation of the two economies and on the first two principal components (i.e. on four factors). Panel B of Table 2 reports the $R^{2}$ coefficients of these regressions. The average of all $R^{2}$ coefficients amounts to roughly $96 \%$. This exercise suggests that four level factors is a reasonable choice. In order to assess the number of uncertainty factors, we conduct a principal component analysis run on market-based variances. Panel $\mathrm{C}$ of Table 2 displays the results of a principal component analysis on market-based variances. Results indicate that the first two principal components explain roughly $90 \%$ of the cross-sectional variation observed in market-based variances.

\section{[Insert Table 2 about here.]}

The fourth remark pertains to the standard deviations of the measurement equations, i.e. to the components of vectors $\sigma^{a v g}$ and $\sigma^{v a r}$ (see eqs. (11) and (12)). In order not to have too large a number of parameters to estimate, these standard deviations are calibrated in a preliminary step. ${ }^{22}$

\section{Results}

\subsection{Estimated model}

Table 3 presents the parameter estimates of the model described in section 4 . Following the previous discussion (4.2.3), we assume that $Y_{t}$ is of dimension four and that $z_{t}$ contains two volatility factors. ${ }^{23}$ We observe that the autoregressive parame-

\footnotetext{
${ }^{22}$ We employ the approach of Green and Silverman (1994) and proceed as follows. We apply a smoothing spline to the raw survey-based expectations and variances $\left(S P F_{t}\right.$ and $\left.V S P F_{t}\right)$. Next, we compute the standard deviations of the differences between the survey-based series and their smoothed counterparts. The standard errors of the measurement equations are set to these values.

${ }^{23}$ The results we hereby disclose are those of a joint estimation for the two currency areas, including both first and second conditional moments of surveys. Individual estimations per country, as well as estimations excluding second conditional moments have been conducted and their results
} 
ters pertaining to the first and fourth factors, namely, $\Phi_{Y}[1,1]$ and $\Phi_{Y}[4,4]$ are close to 1, suggesting these factors appear to be very persistent in our estimation.

\section{[Insert Table 3 about here.]}

Figure 1 displays the factor loadings of the estimated model. The first factor appears to be the most important one both for the euro area (top left panel) and for the United States (top right panel). This factor has a similar loading for both economies: the factor is important at shorter horizons and becomes monotonically less important as the horizon lengthens. The second most important factor is the third one for the euro area and the fourth one for the U.S. economy, and the importance of both factors is declining with the horizon as well, although the U.S-related second factor appears to be stronger than the euro-area-related second factor. Overall, evidence on the top panels of Figure 1 suggests that U.S. conditional expectations load more on the variety of factors than euro-area expectations. The two middle panels suggest that the first volatility factor is the most important one for conditional inflation expectations at short- to medium-term horizons (roughly up to about 5 years) for both economies. The second volatility factor is somewhat important for driving U.S. conditional inflation expectations at shorter horizons (roughly up to 3 years) but does not appear to be important for driving conditional expectations in the euro area. Lastly, the bottom two charts show the volatility factors' loadings for the conditional variances. The first volatility factor appears to be driving conditional variances with a slightly hump-shaped pattern picking up at a 2- and 3-year horizon in the euro area, while the second volatility factor is almost insignificant in the euro-area case. In the case of U.S. conditional variances, both factors appear to be as important at very short horizons (up to 2 years), but then the first factor behaves in a hump-shaped pattern picking up at a 3- to 4-year horizon, while the second factor is monotonically declining.

\section{[Insert Figure 1 about here.]}

are qualitatively similar. We opt for the joint specification including second conditional moments as it allows for interesting studies of inflation co-movements and uncertainty. Results of these robustness checks are available upon request. 
The fit of surveys is illustrated in Figure 2. This figure shows realized inflation (top panels), the fit of one-year-ahead conditional inflation expectations and variances for both areas (panel rows 2 and 3 in the figure), and, lastly, the fit of conditional expectations and variances for one-year four years forward and five-year five years forward inflation rates in the euro area and United States, respectively (panel rows 4 and 5 in the figure). Note that the definition of inflation forecasts, both across areas and surveys, differs and, thus, the outputs are not directly comparable. Even though the model is fitting the first two moments of several types of inflation expectations across different economies, the fit is quite satisfactory.

\section{[Insert Figure 2 about here.]}

\subsection{Model-implied conditional distributions}

Figure 3 compares the one-year ahead survey-based inflation histograms to the oneyear ahead model-implied distributions of inflation for two dates (i.e. one in the beginning and one at the end of our sample). Specifically, the top chart displays euroarea distributions as of February 2005 and April 2016, while the bottom chart shows U.S. distributions as of January 2005 and January 2016. ${ }^{24}$ For the model-implied distributions, two-standard-deviation confidence intervals are reported. These standard deviations reflect uncertainty associated with the estimation of the latent factors $X_{t}$ and are obtained by applying the delta method on the function relating $X_{t}$ factors to the conditional cumulative distribution function (c.d.f.) of future inflation. ${ }^{25}$ Note that raw survey data are not comparable across areas unless the inflation measure is the same, which is not the case here. By contrast, as will be exploited below, our model generates moments of inflation distributions that are adequately comparable

\footnotetext{
${ }^{24}$ We cannot use the same months for both areas because surveys that feature histograms are not released on the same months in the United States and in the euro area. The first selected dates - namely February 2005 for the euro area and January 2005 for the United States - are chosen because they correspond to periods where inflation uncertainty was rather low as compared to the end-of-sample dates.

${ }^{25}$ The covariance matrix of the smoothed values of $X_{t}$ (i.e. $\mathbb{E}\left(X_{t} \mid S_{T}\right)$, where $T$ is the length of our sample) stems from the Kalman smoothing algorithm (Harvey, 1989). Appendix 7.3 details the computation of the c.d.f. of future inflation rates.
} 
across economies. Both economies' distributions have shifted noticeably to the left from 2005 to 2016, suggesting a decline in inflation expectations. The euro-area's inflation distribution flattened, indicating an increase in the variance of inflation expectations and, thus, greater inflation uncertainty. Similar findings are reported in Rich, Song, and Tracy (2012), where they find that uncertainty measures stemming from the ECB's survey of professional forecasters display countercyclical behavior and find evidence of increased inflation uncertainty since 2007.

\section{[Insert Figure 3 about here.]}

Figure 4 displays model-implied spot inflation expectations (top charts) and oneyear forward inflation expectations (bottom charts) for two dates: November 2004 and April 2016 for the euro area and January 2005 and January 2016 for the United States. The figure also displays the 5th and 95th quantiles associated with the conditional distributions. ${ }^{26}$ The top charts demonstrate that survey-based inflation expectations declined noticeably on short to intermediate horizons (up to roughly 5 years) in the past decade and also declined on longer horizons (5 to 10 years), but to a lesser extent. Moreover, the top panels indicate that the term structure of euro-area inflation expectations is flatter relative to the United States. Specifically, euro-area inflation expectations at intermediate- and long-horizons have on average been lower than those in the United States despite the fact that the short (1- to 2-year) expected inflation rates have been comparable. The bottom two charts indicate that one-year forward expected inflation rates declined notably at short- to intermediate- horizons, but little moved on longer horizons, over the past decade.

\section{[Insert Figure 4 about here.]}

Figure 5 displays model-implied variances of spot inflation expectations (top charts) and one-year forward inflation expectations (bottom charts) for the same two dates as in Figure 4. We interpret these variances as inflation uncertainty about

\footnotetext{
${ }^{26}$ The quantiles are derived from closed-form formulas given in Appendix 7.3.
} 
expected inflation rates. ${ }^{27}$ This figure demonstrates a few interesting points. First, according to the top charts, inflation uncertainty has been higher in the United States than in the euro area at all horizons. Second, in the past decade, U.S. inflation uncertainty declined at horizons up to 6 years and slightly rose at longer horizons. At the same time, euro-area inflation uncertainty increased and more so at short- to intermediate-horizons. ${ }^{28}$ Third, euro-area uncertainty associated with the one-year forward inflation rates increased about uniformly at all horizons, while their U.S. counterparts declined at shorter horizons but increased at longer horizons.

\section{[Insert Figure 5 about here.]}

Figure 6 compares model-implied (physical) probabilities of negative and lower than 1 percent future inflation rates to their risk-neutral counterparts. These are provided for one- and three-year ahead horizons. The risk-neutral probabilities are based on inflation derivatives, namely, zero-coupon inflation swaps and inflation floors. ${ }^{29}$ The grey shaded areas represent two-standard-deviation confidence intervals for model-implied probabilities. ${ }^{30}$ Unsurprisingly, low inflation probabilities are higher in the short run than in the long run. Both economies faced high low-inflation probabilities shortly after the Lehman Brothers collapse. Importantly, risk-neutral probabilities are higher than their physical counterparts and their difference is substantial. Similarly, Kitsul and Wright (2013) and Fleckenstein, Longstaff, and Lustig (2013) find that risk-neutral probabilities assign larger values to tail events (either deflation or high inflation) relative to their time series counterparts, supporting a U-shaped empirical pricing kernel. This is consistent with the fact that the defla-

\footnotetext{
${ }^{27}$ Appendix 7.5 provides details on the definition of the uncertainty measure.

${ }^{28}$ This point is also confirmed by 5 th and 95 th percentile bounds in Figure 4, where uncertainty associated with the expected inflation rates has been lower on the long end of the term structure of expectations in the two economies.

${ }^{29}$ The risk-neutral distributions - more precisely the forward-neutral distributions- are assumed to be of the generalised Beta type (see Appendix 7.6). These distributions are specified by four parameters. For each area, each date and each maturity, these four parameters are chosen so as to minimise the weighted sum of squared pricing errors. The generalised Beta distribution features a compact support; however, the parameterisation potentially allows for wide supports, thereby making extreme inflation outcomes possible (if supported by the data).

${ }^{30}$ These standard deviations are obtained by applying the delta method on the function relating $X_{t}$ factors to the conditional cumulative distribution function (c.d.f.) of future inflation.
} 
tion state (or high inflation state) is perceived by agents as a bad state of the world, characterized by a high rate of marginal utility.

\section{[Insert Figure 6 about here.]}

The first three panels in Figure 7 display conditional variances, covariances and correlations of future inflation rates for the two areas. The bottom panel shows the times series of the joint probability of deflation, i.e. $\mathbb{P}\left(\pi_{t+h}^{(E . A .)} \leq 0, \pi_{t+h}^{(U . S .)} \leq 0 \mid \underline{X_{t}}\right) .{ }^{31}$ We plot these series for one-year ( $h=12$ months) and five-year ( $h=60$ months) horizons. Our model reveals that there are differences in uncertainty measures. ${ }^{32}$ Although we observe some convergence in uncertainty measures over the next five years across the two areas (see top panel), with the U.S. variances of inflation declining and the euro-area variances slightly increasing, the euro-area variances remain smaller. This may be explained by the average lower level of inflation in the euro area and also by the absence of the explicit inflation target in the United States, that was only adopted in January 2012. ${ }^{33}$ We also find that the variances of one-year ahead inflation converged toward the end of our sample, in the late 2015 to mid-2016. This seems to suggest that uncertainty about near-term inflation is similar in the two areas. The correlation between euro-area and U.S. inflation rates appears substantial, ranging from about 60 percent to about 75 percent. This finding supports the idea of joint inflation movements due to the interdependent nature of economies nowadays and is in line with earlier findings (e.g., Monacelli and Sala, 2009; Ciccarelli and Mojon, 2010) that also show substantial commonalities in inflation movements of industrialized countries. The joint deflation probability in the United States and the euro area varies a lot during our sample period, especially for the one-year ahead horizon. However, in the period surrounding the euro-area crisis period, 2012-2014,

\footnotetext{
${ }^{31}$ Because we (the econometricians) do not perfectly observe $X_{t}$, what is displayed in Figure 7 is actually an estimate of $\mathbb{P}\left(\pi_{t+h}^{(E . A .)} \leq 0, \pi_{t+h}^{(U . S .)} \leq 0 \mid \underline{X_{t}}\right)$. To make it clear, let us denote by $f\left(X_{t}\right)$ the function that is such that $f\left(X_{t}\right)=\mathbb{P}\left(\pi_{t+h}^{(E . A .)} \leq 0, \pi_{t+h}^{(U . S .)} \leq 0 \mid X_{t}\right)$; then Figure 7 displays $f\left(\mathbb{E}\left(X_{t} \mid \underline{S_{T}}\right)\right)$ where $T$ is the length of our sample and $\mathbb{E}\left(X_{t} \mid \underline{S_{T}}\right)$ therefore is the Kalman-smoothed estimate of $X_{t}$ (Harvey, 1989).

${ }^{32}$ Raw data stemming from surveys do not allow to carry out comparisons because surveys are different in nature and cannot be directly compared.

${ }^{33}$ See the January 25, 2012 Monetary Policy Press Release http://www.federalreserve.gov/ newsevents/press/monetary/20120125c.htm.
} 
(indicated by the pink bar on the charts) the joint deflation probability five years ahead is higher than the one for the one-year ahead horizon. At the height of the financial crisis in 2009 and in the beginning of 2016 the joint deflation probability one-year ahead becomes substantially higher than its five-year ahead counterpart. Finally, at the end of our sample, in mid-2016, the joint deflation probability does not exceed 2 percent at either horizons.

\section{[Insert Figure 7 about here.]}

Table 4 reports regression results that relate deflation probabilities, inflation covariances and inflation variances to various explanatory variables. We find that Economic Policy Uncertainty (EPU), inflation risk premia and sentiment indices have a higher explanatory power relative to the stock markets' volatility when it comes to co-movement indicators such as joint deflation probabilities and covariances as well as individual deflation probabilities and variances. ${ }^{34}$ EPU indices are positively correlated with and particularly interesting for the five-year (joint and area-specific) deflation probabilities, as well as for inflation covariances, euro-area inflation variances and U.S. five-year inflation variances. Both euro-area and U.S. economic sentiment indices have low explanatory power for joint and euro-area deflation probabilities, but high explanatory power for one-year ahead inflation covariances and U.S. variances. Moreover, area-specific inflation risk premia are relevant for deflation probabilities and variances of that particular economy. Interestingly, we also find that euro-area indicators (i.e. EPU and risk premia) seem to be more useful in explaining joint and U.S. deflation probabilities than their U.S. counterparts, suggesting interactions between the two economies.

\section{[Insert Table 4 about here.]}

Figure 8 reports time-series of conditional probabilities of future inflation rates

\footnotetext{
${ }^{34}$ Note that Charemza, Díaz, and Makarova (2015) find a puzzling lack of correlation between inflationary forecast errors and the EPU index for Canada.
} 
being in a certain range, ${ }^{35}$

$$
\mathbb{P}\left(\pi_{t+h-m, t+h}^{(i)} \in I_{j} \mid \underline{X_{t}}\right), \quad j=1,2,
$$

where $h$ is the horizon measured in months, $m$ is the tenor of the future expected rate measured in months, $I_{1}=[1.5 \%, 2.5 \%]$ and $I_{2}=[1 \%, 3 \%]$. We suggest that these conditional probabilities of future inflation rates (that can be computed for any horizon) capture the spirit of the anchoring of inflation expectations while accounting for uncertainty around inflation expectations. We thus propose using these probabilities to gauge the anchoring of inflation expectations.

The European Central Bank adopted a medium-term inflation target in May 2003, formulated as follows: "The primary objective of the ECB's monetary policy is to maintain price stability. The ECB aims at inflation rates of below, but close to, 2\% over the medium term." "36 The Federal Reserve adopted a longer-run inflation target in January 2012, stated as follows: "The inflation rate over the longer run is primarily determined by monetary policy and hence the Committee has the ability to specify a longer-run goal for inflation. The Committee judges that inflation at the rate of 2 percent, as measured by the annual change in the price index for personal consumption expenditures, is most consistent over the longer run with the Federal Reserve's statutory mandate." ${ }^{\prime 37}$ Thus, the ECB and the Fed target inflation over somewhat different periods. We interpret the "medium-term" as the one-year four years ahead inflation and the "long-term" as the average annual inflation five-year five years ahead. We plot conditional probabilities (see eq. (14)) for one-year four years ahead inflation (black solid line), for five-year five years ahead inflation (dotted line) and for one-year nine years ahead inflation (grey solid line). The latter horizon was used by Beechey, Johannsen, and Levin (2011) to study the anchoring of inflation expectations as the sensitivity of interest rates and inflation compensation to macroeconomic news releases. ${ }^{38}$

\footnotetext{
${ }^{35}$ The same comment as in Footnote 31 applies.

${ }^{36}$ See https://www.ecb.europa.eu/mopo/html/index.en.html.

${ }^{37}$ See https://www. federalreserve.gov/newsevents/press/monetary/20120125c.htm.

${ }^{38}$ Our approach is fundamentally different as our measure is available only at monthly frequency
} 
Overall, Figure 8 conveys a few interesting findings. First, the probabilities of inflation expectations have been higher throughout our sample in the euro area than in the United States. Second, the $I_{1}$ and $I_{2}$-range euro-area probabilities have decreased by up to 10 percent at the considered horizons since the end of 2008 . This finding appears to be in line with Eyziak and Paloviita (2016), where the authors find that euro-area long-term inflation forecasts are found to be more sensitive to shorter-term forecasts and to the realized HICP inflation in the post-crisis period. Third, probabilities of the one-year ahead inflation either four years or nine years ahead declined slightly in the euro area and increased somewhat in the United States. Nevertheless, such probabilities are notably higher in the euro area (around 0.6) than in the Untied States (around 0.4), according to the $I_{1}$ range. The results are qualitatively similar for the $I_{2}$ range. Fourth, the U.S. $I_{1}$ probability of five-year five years ahead inflation has increased substantially after the introduction of the explicit inflation target by the Fed and exceeded its pre-crisis levels towards the end of our sample, in 2016. Fifth, the euro-area $I_{1}$ probability of the five-year five years ahead inflation is still found to be a touch higher compared to the United States towards the end of our sample (despite an increase in probabilities in the United States), suggesting that euro-area inflation expectations still remain somewhat better anchored. These results are in line with the findings of Beechey, Johannsen, and Levin (2011) and Buono and Formai (2016). Finally, a post-crisis increase in the anchoring probabilities of the U.S. future inflation rates may potentially reflect an explicit inflation target announced by the Federal Open Market Committee in January 2012.

\section{[Insert Figure 8 about here.]}

and, therefore, cannot be used to study the responsiveness of inflation expectations to macro news. 


\section{Conclusion}

We build a dynamic latent factor model with stochastic volatility for the joint estimation of inflation expectations and inflation uncertainty in the United States and the euro area. Our model produces survey-consistent measures of inflation expectations and of inflation uncertainty in the two currency areas that are comparable across surveys and areas. We use different types of inflation projections from surveys of professional forecasters to fit the first and second moments of distributions of future inflation rates. We find strong commonalities in the movements of inflation expectations and inflation uncertainty in both economies over our sample period of 1999-2016. Our model-implied estimates suggest that since 2010 short- and intermediate-term inflation expectations moved down noticeably in both economies, while long-term inflation expectations remained stable. U.S. inflation uncertainty declined substantially over our sample period but still remains higher than euroarea inflation uncertainty, despite a noticeable increase in the latter one. Over time, post-financial-crisis inflation expectations in the United States became more anchored, while euro-area inflation expectations — slightly less anchored. Probabilities of deflation varied substantially over our sample period, especially during the financial crisis, declining to low levels toward the end of our sample in 2016. Our findings should be interesting to market participants, policymakers and anyone who regularly assesses inflation expectations and uncertainty as our measures can be regularly updated. 


\section{References}

Andrade, P., V. Fourel, E. Ghysels, and J. Idier, 2014, "The Financial Content of Inflation Risks in the Euro Area," International Journal of Forecasting, 30(3), 648-659.

Andrade, P., and H. Le Bihan, 2013, "Inattentive Professional Forecasters," Journal of Monetary Economics, 60(8), 967 - 982.

Ang, A., G. Bekaert, and M. Wei, 2007, "Do Macro Variables, Asset Markets, or Surveys Forecast Inflation Better?," Journal of Monetary Economics, 54(4), 1163-1212.

— , 2008, "The Term Structure of Real Rates and Expected Inflation," Journal of Finance, 63(2), 797-849.

Aruoba, S. B., 2016, "Term structures of inflation expectations and real interest rates," Working Papers 16-9, Federal Reserve Bank of Philadelphia.

Baker, S. R., N. Bloom, and S. J. Davis, 2016, "Measuring Economic Policy Uncertainty," The Quarterly Journal of Economics, forthcoming.

Beechey, M. J., B. K. Johannsen, and A. T. Levin, 2011, "Are Long-run Inflation Expectations Anchored More Firmly in the Euro Area than in the United States?," American Economic Journal: Macroeconomics, 3(2), 104-29.

Bekaert, G., and E. Engstrom, 2010, "Inflation and the Stock Market: Understanding the Fed Model," Journal of Monetary Economics, 57(3), 278-294.

Bernanke, B. S., 2007, "Inflation Expectations and Inflation Forecasting," Cambridge, Massachusetts.

Boero, G., J. Smith, and K. F. Wallis, 2014, "The Measurement and Characteristics of Professional Forecasters' Uncertainty," Journal of Applied Econometrics, doi: 10.1002/jae.2400.

Brissimis, S. N., and N. S. Magginas, 2008, "Inflation Forecasts and the New Keynesian Phillips Curve," International Journal of Central Banking, 4(2), 1-22.

Buono, I., and S. Formai, 2016, "The Evolution of the Anchoring of Inflation Expectations," Bank of Italy Occasional Paper, (321).

Buraschi, A., and A. Jiltsov, 2005, "Inflation Risk Premia and the Expectation Hypothesis," Journal of Financial Economics, 75, 429-490.

Buraschi, A., and P. Whelan, 2012, "Term Structure Models with Differences in Beliefs," Working paper, Imperial College London.

Campbell, J. Y., A. Sunderam, and L. M. Viceira, 2013, "Inflation Bets or Deflation Hedges? The Changing Risks of Nominal Bonds," Working Paper 14701, National Bureau of Economic Research.

Campbell, J. Y., and L. M. Viceira, 2001, "Who Should Buy Long-Term Bonds?," American Economic Review, 91(1), 99-127.

Capistrán, C., and A. Timmermann, 2009, "Disagreement and Biases in Inflation Expectations," Journal of Money, Credit and Banking, 41(2-3), 365-396. 
Caporale, G., L. Onorante, and P. Paesani, 2012, "Inflation and Inflation Uncertainty in the Euro Area," Empirical Economics, 43(2), 597-615.

Charemza, W., C. Díaz, and S. Makarova, 2015, "Conditional Term Structure of Inflation Forecast Uncertainty: The Copula Approach," Discussion Papers in Economics 15/07, Department of Economics, University of Leicester.

Chernov, M., and P. Mueller, 2012, "The Term Structure of Inflation Expectations," Journal of Financial Economics, 106(2), 367-394.

Chun, A. L., 2011, "Expectations, Bond Yields, and Monetary Policy," Review of Financial Studies, 24(1), 208-247.

—_ 2012, "Forecasting Interest Rates and Inflation: Blue Chip Clairvoyants or Econometrics?," Working Paper.

— , 2014, "A Forward-Looking Model of the Term Structure of Interest Rates," Working Paper.

Ciccarelli, M., and B. Mojon, 2010, "Global Inflation," The Review of Economics and Statistics, 92(3), 524-535.

Clements, M. P., 2014, "Probability Distributions or Point Predictions? Survey Forecasts of U.S. Output Growth and Inflation," International Journal of Forecasting, 30(1), 99-117.

Conflitti, C., 2011, "Measuring Uncertainty and Disagreement in the European Survey and Professional Forecasters," OECD Journal: Journal of Business Cycle Measurement and Analysis, 2011(2010-034), 69-103.

Cox, J. C., J. E. Ingersoll, and S. A. Ross, 1985, "An Intertemporal General Equilibrium Model of Asset Prices," Econometrica, 53(2), 363-84.

Croushore, D., 2010, "An Evaluation of Inflation Forecasts Using Real-time Data," BE Journal of Macroeconomics, Contributions, 10.

Crump, R. K., S. Eusepi, and E. Moench, 2016, "The Term Structure of Expectations and Bond Yields," Federal Reserve Bank of New York Staff Report No. 775.

D'Amico, S., D. H. Kim, and M. Wei, 2016, "Tips from TIPS: The Informational Content of Treasury Inflation-Protected Security Prices," Journal of Financial and Quantitative Analysis, forthcoming.

D'Amico, S., and A. Orphanides, 2014, "Inflation Uncertainty and Disagreement in Bond Risk Premia," working paper, Working paper 2014-24, Federal Reserve Bank of Chicago.

de Jong, F., 2000, "Time Series and Cross-Section Information in Affine Term-Structure Models," Journal of Business \& Economic Statistics, 18(3), 300-314.

De Pooter, M., P. Robitaille, I. Walker, and M. Zdinak, 2014, "Are Long-Term Inflation Expectations Well Anchored in Brazil, Chile, and Mexico?," International Journal of Central Banking, 10(2), 337-400.

Del Negro, M., and S. Eusepi, 2011, "Fitting Observed Inflation Expectations," Journal of Economic Dynamics and Control, 35(12), 2105-2131. 
Del Negro, M., M. P. Giannoni, and F. Schorfheide, 2015, "Inflation in the Great Recession and New Keynesian Models," American Economic Journal: Macroeconomics, 7(1), 168 96.

Duan, J.-C., and J. G. Simonato, 1999, "Estimating Exponential-Affine Term Structure Models by Kalman Filter," Review of Quantitative Finance and Accounting, 13(2), 111135.

Duffee, G. R., and R. H. Stanton, 2012, "Estimation of Dynamic Term Structure Models," Quarterly Journal of Finance, 2(2).

Duffie, D., J. Pan, and K. Singleton, 2000, "Transform Analysis and Asset Pricing for Affine Jump-Diffusions," Econometrica, 68(6), 1343-1376.

Engelberg, J., C. F. Manski, and J. Williams, 2009, "Comparing the Point Predictions and Subjective Probability Distributions of Professional Forecasters," Journal of Business $\mathcal{E}^{3}$ Economic Statistics, 27, 30-41.

Engle, R. F., 1982, "Autoregressive Conditional Heteroscedasticity with Estimates of the Variance of United Kingdom Inflation," Econometrica, 50(4), 987-1007.

Faust, J., and J. Wright, 2009, "Comparing Greenbook and Reduced Form Foreacasts Using a Large Real-time Data Set," Journal of Business and Economic Statistics, 27(4), $468-479$.

Faust, J., and J. H. Wright, 2013, "Forecasting Inflation," Handbook of economic forecasting, 2(Part A), 3-56.

Fleckenstein, M., F. A. Longstaff, and H. Lustig, 2013, "Deflation Risk," NBER Working Paper 19238, National Bureau of Economic Research.

Giordani, P., and P. Soderlind, 2003, "Inflation Forecast Uncertainty," European Economic Review, 47(6), 1037-1059.

Gouriéroux, C., and J. Jasiak, 2006, "Autoregressive Gamma Processes," Journal of Forecasting, 25, 129-152.

Grant, A. P., and L. B. Thomas, 1999, "Inflation Expectations and Rationality Revisited," Economic Letters, 62, 331-338.

Green, P. J., and B. W. Silverman, 1994, Nonparametric Regression and Generalized Linear Models: A Roughness Penalty Approach. Chapman and Hall.

Grishchenko, O. V., and J.-Z. Huang, 2013, "Inflation Risk Premium: Evidence from the TIPS Market," Journal of Fixed Income, 22(4), 5-30.

Grishchenko, O. V., J. M. Vanden, and J. Zhang, 2016, "The informational Content of the Embedded Deflation Option in TIPS," Journal of Banking and Finance, 65, 1-26.

Gürkaynak, R., A. T. Levin, A. N. Marder, and E. T. Swanson, 2007, "Inflation Targeting and the Anchoring of Inflation Expectations in the Western Hemisphere," Economic Review, pp. 25-47.

Harvey, A. C., 1989, Forecasting, Structural Time Series Models and the Kalman Filter. Cambridge University press, cambridge edn. 
Harvey, A. C., and R. G. Pierse, 1984, "Estimating Missing Observations in Economic Time Series," Journal of the American Statistical Association, 79, 1-36.

Haubrich, J., G. Pennacchi, and P. Ritchken, 2012, "Inflation Expectations, Real Rates, and Risk Premia: Evidence from Inflation Swaps," Review of Financial Studies, 25(5), $1588-1629$.

Hördahl, P., and O. Tristani, 2010, "Inflation Risk Premia in the U.S. and the Euro Area," ECB Working Paper Series No. 1270.

Kim, D. H., and A. Orphanides, 2012, "Term Structure Estimation with Survey Data on Interest Rate Forecasts," Journal of Financial and Quantitative Analysis, 47(01), 241272 .

Kitsul, Y., and J. H. Wright, 2013, "The economics of Options-implied Inflation Probability Density Functions," Journal of Financial Economics, 110(3), 696-711.

Kumar, S., H. Afrouzi, O. Coibion, and Y. Gorodnichenko, 2015, "Inflation Targeting Does Not Anchor Inflation Expectations: Evidence from Firms in New Zealand," Brookings Papers on Economic Activity, 51(2), 151-225.

Lahiri, K., and X. Sheng, 2010, "Measuring Forecast Uncertainty by Disagreement: The Missing Link," Journal of Applied Econometrics, 25(4), 514-538.

Łyziak, T., and M. Paloviita, 2016, "Anchoring of Inflation Expectations in the Euro Area: Recent Evidence Based on Survey Data," Working Paper Series 1945, European Central Bank.

Mehra, Y. P., 2002, "Survey Measures of Expected Inflation: Revisiting the Issues of Predictive Content and Rationality," FRB Richmond Economic Quarterly, 88(3), 1736.

Mehrotra, A., and J. Yetman, 2014, "Decaying Expectations: What Inflation Forecasts Tell us about the Anchoring of Inflation Expectations," BIS Working Papers 464, Bank for International Settlements.

Mertens, E., 2016, "Measuring the Level and Uncertainty of Trend Inflation," Review of Economics and Statistics, (5), 950-967.

Mishkin, F., 2007, "Inflation Dynamics," NBER Working Papers 13147, National Bureau of Economic Research, Inc.

Monacelli, T., and L. Sala, 2009, "The International Dimension of Inflation: Evidence from Disaggregated Consumer Price Data," Journal of Money, Credit and Banking, 41(s1), $101-120$.

Monfort, A., F. Pegoraro, J.-P. Renne, and G. Roussellet, 2017, "Staying at Zero with Affine Processes: An Application to Term-Structure Modelling," Journal of Econometrics, forthcoming.

Nagel, S., 2016, "Long-Run Inflation Uncertainty," International Journal of Central Banking, 12(3), 207-217.

Piazzesi, M., J. Salomao, and M. Schneider, 2015, "Trend and Cycle in Bond Premia," working paper. 
Piazzesi, M., and M. Shneider, 2007, "Equilibrium Yield Curves," in NBER Macroeconomics Annual. MIT Press, Cambridge, vol. 21, pp. 389-472.

Rich, R., J. Song, and J. Tracy, 2012, "The Measurement and Behavior of Uncertainty: Evidence from the ECB Survey of Professional Forecasters," Staff Report 588, Federal Reserve Bank of New York.

Roberts, J. M., 1995, "New Keynesian Economics and the Phillips Curve," Journal of Money, Credit and Banking, 27(4), 975-84.

Rudebusch, G., and E. Swanson, 2008, "Examining the Bond Premium Puzzle with a DSGE Model," Journal of Monetary Economics, 55, S111-S126.

Shi, Z., 2014, "Time-Varying Ambiguity and Asset Pricing Puzzles," Working paper, Ohio State University.

Speck, C., 2016, "Inflation Anchoring in the Euro Area," Discussion Papers 04/2016, Deutsche Bundesbank, Research Centre.

Stock, J. H., and M. W. Watson, 2007, "Why has U.S. Inflation Become Harder to Forecast?," Journal of Money, Credit and Banking, 39(s1), 3-33.

Thomas, L. B., 1999, "Survey Measures of Expected U.S. Inflation," Journal of Economic Perspectives, 13(4), 125-144.

Wright, J. H., 2011, "Term Premia and Inflation Uncertainty: Empirical Evidence from an International Panel Dataset," American Economic Review, 101(4), 1514-34.

Zarnowitz, V., and L. A. Lambros, 1987, "Consensus and Uncertainty in Economic Prediction," Journal of Political Economy, 95(3), 591-621.

Zhou, H., 2001, "A Study of the Finite Sample Properties of EMM, GMM, QMLE, and MLE for a Square-root Interest Rate Diffusion Model," Journal of Computational Finance, 5, 99-122. 


\section{Appendix}

\subsection{Conditional means and variances of $X_{t}$}

In this appendix we compute conditional expectations and variances of linear combinations of future $X_{t} \mathrm{~s}$. Formally, we consider the first two moments of the random variable $\sum_{i=1}^{h} \gamma_{i}^{\prime} X_{t+i}$ conditionally on the information available as of date $t$ (i.e. $\underline{X_{t}}$ ).

Appendix 7.1.1 shows that $X_{t}$ is an affine process. This property implies that the first two conditional moments of $X_{t}$ are affine in $X_{t}$. That is, there exist functions $a_{h}, b_{h}, \alpha_{h}$ and $\beta_{h}$ such that, for any set of $\gamma_{i}$ s:

$$
\begin{aligned}
\mathbb{E}_{t}\left(\sum_{i=1}^{h} \gamma_{i}^{\prime} X_{t+i}\right) & =a_{h}\left(\gamma_{1}, \ldots, \gamma_{h}\right)+b_{h}\left(\gamma_{1}, \ldots, \gamma_{h}\right)^{\prime} X_{t} \\
\mathbb{V}_{t}\left(\sum_{i=1}^{h} \gamma_{i}^{\prime} X_{t+i}\right) & =\alpha_{h}\left(\gamma_{1}, \ldots, \gamma_{h}\right)+\beta_{h}\left(\gamma_{1}, \ldots, \gamma_{h}\right)^{\prime} X_{t} .
\end{aligned}
$$

Appendix 7.1.2 (Appendix 7.1.3) provides the recursive formulas that can be used to compute $a_{h}$ and $b_{h}\left(\alpha_{h}\right.$ and $\left.\beta_{h}\right)$.

\subsubsection{Affine property of $X_{t}$}

Showing that $X_{t}$ has an affine dynamics amounts to showing that the Laplace transform of $X_{t+1}$, conditional on $\underline{X_{t}}$, is exponential affine in $X_{t}$.

Lemma 7.1 The Laplace transform of $X_{t+1}$, conditional on $X_{t}$, is given by:

$$
\begin{aligned}
& \mathbb{E}\left(\exp \left(u^{\prime} X_{t+1}\right) \underline{\underline{X_{t}}}\right) \\
= & \exp \left(u_{Y}^{\prime} \Phi_{Y} Y_{t}+b_{z}\left(u_{z}+\Theta^{\prime} u_{Y}+0.5 \Gamma_{Y, 1} u_{Y}^{2}\right)^{\prime} z_{t}+\right. \\
& \left.a_{z}\left(u_{z}+\Theta^{\prime} u_{Y}+0.5 \Gamma_{Y, 1} u_{Y}^{2}\right)-u_{Y}^{\prime} \Theta \bar{z}+0.5 \Gamma_{Y, 0}^{\prime} u_{Y}^{2}\right),
\end{aligned}
$$

where $u=\left(u_{Y}^{\prime}, u_{z}^{\prime}\right)^{\prime}, u_{Y}^{2}=u_{Y} \odot u_{Y}$ (by abuse of notation), $\Gamma_{Y}$ is a $q \times n$ matrix and where the functions $a_{z}$ and $b_{z}$ define the conditional Laplace transform of $z_{t}$ (see Appendix 7.2, eq. (18) and (19)). 
Proof We have:

$$
\begin{aligned}
& \mathbb{E}\left(\exp \left(u^{\prime} X_{t+1}\right) \mid \underline{X_{t}}\right) \\
= & \mathbb{E}\left(\exp \left(u_{Y}^{\prime} Y_{t+1}+u_{z}^{\prime} z_{t+1}\right) \mid \underline{X_{t}}\right) \\
= & \mathbb{E}\left(\mathbb{E}\left[\exp \left(u_{Y}^{\prime} Y_{t+1}+u_{z}^{\prime} z_{t+1}\right) \underline{\underline{X}}, z_{t+1}\right] \underline{\underline{X_{t}}}\right) \\
= & \exp \left(u_{Y}^{\prime}\left\{\Phi_{Y} Y_{t}-\Theta \bar{z}\right\}\right) \mathbb{E}\left(\exp \left(\left(u_{z}+\Theta^{\prime} u_{Y}\right)^{\prime} z_{t+1}+0.5 u_{Y}^{\prime} \operatorname{diag}\left(\Gamma_{Y, 0}+\Gamma_{Y, 1}^{\prime} z_{t+1}\right) u_{Y}\right) \mid \underline{X_{t}}\right) \\
= & \exp \left(u_{Y}^{\prime} \Phi_{Y} Y_{t}+b_{z}\left(u_{z}+\Theta^{\prime} u_{Y}+0.5 \Gamma_{Y, 1} u_{Y}^{2}\right)^{\prime} z_{t}+\right. \\
& \left.a_{z}\left(u_{z}+\Theta^{\prime} u_{Y}+0.5 \Gamma_{Y, 1} u_{Y}^{2}\right)-u_{Y}^{\prime} \Theta \bar{z}+0.5 \Gamma_{Y, 0}^{\prime} u_{Y}^{2}\right),
\end{aligned}
$$

which leads to the result.

The fact that $X_{t}$ follows an affine process implies the following result.

Lemma 7.2 The multi-horizon Laplace transforms of $X_{t}$, conditional on $\underline{X_{t}}$, are exponential affine in $X_{t}$. Specifically, for any set of vectors $u_{i}, i \in[1, h]$, we have:

$$
\mathbb{E}\left(\exp \left(u_{1}^{\prime} X_{t+1}+\cdots+u_{h}^{\prime} X_{t+h}\right) \mid \underline{X_{t}}\right)=\exp \left(A_{h}\left(u_{1}, \ldots, u_{h}\right)+B_{h}\left(u_{1}, \ldots, u_{h}\right)^{\prime} X_{t}\right),
$$

where the functions $A_{i}$ and $B_{i}$ are given by:

$$
\left\{\begin{array}{l}
A_{h}\left(\left[u_{Y}^{\prime}, u_{z}^{\prime}\right]^{\prime}\right)=a_{z}\left(u_{z}+\Theta^{\prime} u_{Y}+0.5 \Gamma_{Y, 1} u_{Y}^{2}\right)-u_{Y}^{\prime} \Theta \bar{z}+0.5 \Gamma_{Y, 0}^{\prime} u_{Y}^{2} \\
B_{h}\left(\left[u_{Y}^{\prime}, u_{z}^{\prime}\right]^{\prime}\right)=\left[u_{Y}^{\prime} \Phi_{Y}, b_{z}\left(u_{z}+\Theta^{\prime} u_{Y}+0.5 \Gamma_{Y, 1} u_{Y}^{2}\right)^{\prime}\right]^{\prime}
\end{array} \quad \text { if } h=1,\right.
$$

and

$$
\left\{\begin{array}{l}
A_{h}\left(u_{1}, \ldots, u_{h}\right)=A_{h-1}\left(u_{2}, \ldots, u_{h}\right)+A_{1}\left(u_{1}+B_{h-1}\left(u_{2}, \ldots, u_{h}\right)\right) \\
B_{h}\left(u_{1}, \ldots, u_{h}\right)=B_{1}\left(u_{1}+B_{h-1}\left(u_{2}, \ldots, u_{h}\right)\right)
\end{array} \quad\right. \text { otherwise. }
$$

Proof eq. (15) proves that Lemma 7.2 is valid for $h=1$. Assume Lemma 7.2 is valid for a given $h \geq 1$, we have:

$$
\begin{aligned}
& \mathbb{E}\left(\exp \left(u_{1}^{\prime} X_{t+1}+\cdots+u_{h+1}^{\prime} X_{t+h+1}\right) \mid \underline{X_{t}}\right) \\
= & \mathbb{E}\left\{\exp \left(u_{1}^{\prime} X_{t+1}\right) \mathbb{E}\left[\exp \left(u_{2}^{\prime} X_{t+2}+\cdots+u_{h+1}^{\prime} X_{t+h+1}\right) \mid \underline{X_{t+1}}\right] \mid \underline{X_{t}}\right\} \\
= & \mathbb{E}\left\{\exp \left(u_{1}^{\prime} X_{t+1}\right) \exp \left(A_{h}\left(u_{2}, \ldots, u_{h+1}\right)+B_{h}\left(u_{2}, \ldots, u_{h+1}\right)^{\prime} X_{t+1}\right) \underline{\mid X_{t}}\right\} \\
= & \exp \left(A_{h}\left(u_{2}, \ldots, u_{h+1}\right)+A_{1}\left(u_{1}+B_{h}\left(u_{2}, \ldots, u_{h+1}\right)\right)+B_{1}\left(u_{1}+B_{h}\left(u_{2}, \ldots, u_{h+1}\right)^{\prime} X_{t}\right)\right),
\end{aligned}
$$

which leads to the result. 


\subsubsection{Computation of $a_{h}$ and $b_{h}$}

We have:

$$
\begin{aligned}
\mathbb{E}_{t}\left(\sum_{i=1}^{h} \gamma_{i}^{\prime} X_{t+i}\right)= & \mathbb{E}_{t}\left(\mathbb{E}_{t+1} \sum_{i=1}^{h} \gamma_{i}^{\prime} X_{t+i}\right) \\
= & \mathbb{E}_{t}\left(\gamma_{1}^{\prime} X_{t+1}+a_{h-1}\left(\gamma_{2}, \ldots, \gamma_{h}\right)+b_{h-1}\left(\gamma_{2}, \ldots, \gamma_{h}\right)^{\prime} X_{t+1}\right) \\
= & a_{h-1}\left(\gamma_{2}, \ldots, \gamma_{h}\right)+a_{1}\left(\gamma_{1}+b_{h-1}\left(\gamma_{2}, \ldots, \gamma_{h}\right)\right)+ \\
& b_{1}\left(\gamma_{1}+b_{h-1}\left(\gamma_{2}, \ldots, \gamma_{h}\right)\right)^{\prime} X_{t}
\end{aligned}
$$

which implies that:

$$
\left\{\begin{array}{l}
a_{h}\left(\gamma_{1}, \ldots, \gamma_{h}\right)=a_{h-1}\left(\gamma_{2}, \ldots, \gamma_{h}\right)+a_{1}\left(\gamma_{1}+b_{h-1}\left(\gamma_{2}, \ldots, \gamma_{h}\right)\right) \\
b_{h}\left(\gamma_{1}, \ldots, \gamma_{h}\right)=b_{1}\left(\gamma_{1}+b_{h-1}\left(\gamma_{2}, \ldots, \gamma_{h}\right)\right)
\end{array}\right.
$$

with $a_{1}(\gamma):=\gamma^{\prime} \mu_{X}$ and $b_{1}(\gamma):=\Phi_{X}^{\prime} \gamma$.

\subsubsection{Computation of $\alpha_{h}$ and $\beta_{h}$}

We have:

$$
\begin{aligned}
\mathbb{V}_{t}\left(\sum_{i=1}^{h} \gamma_{i}^{\prime} X_{t+i}\right)= & \mathbb{V}_{t}\left(\mathbb{E}_{t+1}\left[\sum_{i=1}^{h} \gamma_{i}^{\prime} X_{t+i}\right]\right)+\mathbb{E}_{t}\left(\mathbb{V}_{t+1}\left[\sum_{i=1}^{h} \gamma_{i}^{\prime} X_{t+i}\right]\right) \\
= & \mathbb{V}_{t}\left(\gamma_{1}^{\prime} X_{t+1}+\mathbb{E}_{t+1}\left[\sum_{i=2}^{h} \gamma_{i}^{\prime} X_{t+i}\right]\right)+\mathbb{E}_{t}\left(\mathbb{V}_{t+1}\left[\sum_{i=2}^{h} \gamma_{i}^{\prime} X_{t+i}\right]\right) \\
= & \alpha_{1}\left(b_{h-1}\left(\gamma_{2}, \ldots, \gamma_{h}\right)+\gamma_{1}\right)+\beta_{1}\left(b_{h-1}\left(\gamma_{2}, \ldots, \gamma_{h}\right)+\gamma_{1}\right)^{\prime} X_{t}+ \\
& \alpha_{h-1}\left(\gamma_{2}, \ldots, \gamma_{h}\right)+a_{1}\left(\beta_{h-1}\left(\gamma_{2}, \ldots, \gamma_{h}\right)\right)+b_{1}\left(\beta_{h-1}\left(\gamma_{2}, \ldots, \gamma_{h}\right)\right)^{\prime} X_{t} .
\end{aligned}
$$

Therefore:

$$
\left\{\begin{array}{c}
\alpha_{h}\left(\gamma_{1}, \ldots, \gamma_{h}\right)=\alpha_{1}\left(b_{h-1}\left(\gamma_{2}, \ldots, \gamma_{h}\right)+\gamma_{1}\right)+\alpha_{h-1}\left(\gamma_{2}, \ldots, \gamma_{h}\right)+ \\
a_{1}\left(\beta_{h-1}\left(\gamma_{2}, \ldots, \gamma_{h}\right)\right) \\
\beta_{h}\left(\gamma_{1}, \ldots, \gamma_{h}\right)=\beta_{1}\left(b_{h-1}\left(\gamma_{2}, \ldots, \gamma_{h}\right)+\gamma_{1}\right)+b_{1}\left(\beta_{h-1}\left(\gamma_{2}, \ldots, \gamma_{h}\right)\right),
\end{array}\right.
$$

where, with $S_{p}=\sum_{i=1}^{p}\left[e_{i}^{(p)} \otimes e_{i}^{(p)}\right] e_{i}^{(p)^{\prime}}$ :

$$
\left\{\begin{array}{l}
\alpha_{1}(\gamma)=\left(\gamma_{Y} \otimes \gamma_{Y}\right)^{\prime}\left[(\Theta \otimes \Theta) S_{q} \Gamma_{z, 0}+S_{n} \Gamma_{Y, 0}+S_{n} \Gamma_{Y, 1}^{\prime} \mu_{z}\right]+\left(\gamma_{z} \otimes \gamma_{z}\right)^{\prime} S_{q} \Gamma_{z, 0} \\
\quad+2\left(\gamma_{z} \otimes \gamma_{Y}\right)^{\prime}\left(I_{q} \otimes \Theta\right) S_{q} \Gamma_{z, 0}, \\
\beta_{1}(\gamma)^{\prime}=\left(\gamma_{Y} \otimes \gamma_{Y}\right)^{\prime}\left[(\Theta \otimes \Theta) S_{q} \Gamma_{z, 1}^{\prime}+S_{n} \Gamma_{Y, 1}^{\prime} \Phi_{z}\right]+\left(\gamma_{z} \otimes \gamma_{z}\right)^{\prime} S_{q} \Gamma_{z, 1}^{\prime} \\
\quad+2\left(\gamma_{z} \otimes \gamma_{Y}\right)^{\prime}\left(I_{q} \otimes \Theta\right) S_{q} \Gamma_{z, 1}^{\prime} .
\end{array}\right.
$$




\subsection{Auto-regressive Gamma processes}

The vector $z_{t}$ follows a multivariate $\operatorname{ARG}_{\nu}(\varphi, \mu)$ process. This process, introduced by Gouriéroux and Jasiak (2006), is the time-discretized Cox, Ingersoll, and Ross (1985) process (see also Monfort, Pegoraro, Renne, and Roussellet (2017)).

Conditionally on $z_{t-1}=\left\{z_{t-1}, z_{t-2}, \ldots\right\}$, the different components of $z_{t}$, denoted by $z_{i, t}$, are independent and drawn from non-centered Gamma distributions, i.e.:

$$
z_{i, t} \mid \underline{z_{t-1}} \sim \gamma_{\nu_{i}}\left(\varphi_{i}^{\prime} z_{t-1}, \mu_{i}\right)
$$

where $\nu, \mu, \varphi_{1}, \ldots, \varphi_{q-1}$ and $\varphi_{q}$ are $q$-dimensional vectors. (Recall that $W$ is drawn from a non-centered Gamma distribution $\gamma_{\nu}(\varphi, \mu)$, iif there exists an exogenous $\mathcal{P}(\varphi)$-distributed variable $Z$ such that $W \mid Z \sim \gamma(\nu+Z, \mu)$ where $\nu+Z$ and $\mu$ are, respectively, the shape and scale parameters of the gamma distribution.)

Importantly, it can be shown that this process is affine, in the sense that its conditional Laplace transform is exponential affine. Formally, the conditional logLaplace transform of $z_{t+1}$, denoted by $\psi_{t}$, is given by:

$$
\psi_{t}(w):=\log \left(E_{t}\left[\exp \left(w^{\prime} z_{t+1}\right)\right]\right)=a_{z}(w)+b_{z}(w)^{\prime} z_{t}
$$

with

$$
\begin{aligned}
& a_{z}(w)=-\nu^{\prime} \log (1-\mu \odot w) \\
& b_{z}(w)=\varphi\left(\frac{w \odot \mu}{1-w \odot \mu}\right)
\end{aligned}
$$

where $\varphi$ is the $q \times q$ matrix equal to $\left[\varphi_{1}, \ldots, \varphi_{q}\right]$, where $\odot$ is the element-by-element (Hadamard) product and where, by abuse of notations, the log and division operator are applied element-by-element wise.

The weak vector auto-regressive (VAR) form of process $z_{t}$ is given by:

$$
z_{t}=\mu_{z}+\Phi_{z} z_{t-1}+\operatorname{diag}\left(\sqrt{\Gamma_{z, 0}+\Gamma_{z, 1}^{\prime} z_{t-1}}\right) \varepsilon_{z, t}
$$

where, conditionally on $z_{t-1}, \varepsilon_{z, t}$ is of mean zero and has a covariance matrix equal to the identity matrix and where:

$\mu_{z}=\mu \odot \nu, \quad \Phi_{z}=\left(\mu \mathbf{1}_{q \times 1}^{\prime}\right) \odot\left(\varphi^{\prime}\right), \quad \Gamma_{z, 0}=\mu \odot \mu \odot \nu \quad$ and $\quad \Gamma_{z, 1}^{\prime}=2\left[(\mu \odot \mu) \mathbf{1}_{q \times 1}^{\prime}\right] \odot\left(\varphi^{\prime}\right)$.

Assuming that the eigenvalues of $\Phi_{z}$ lie (strictly) within the unit circle, this last formula notably implies that the unconditional mean of $z_{t}$ is equal to $\left(I_{q}-\Phi_{z}\right)^{-1} \mu_{z}$ whilst $z_{t}$ 's unconditional variance is equal to $\left(I_{q^{2}}-\Phi_{z} \otimes \Phi_{z}\right)^{-1} S_{q}\left(\Gamma_{z, 0}+\Gamma_{z, 1}^{\prime} \bar{z}\right)$. 


\subsection{Computation of model-implied conditional distributions}

In the model, inflation rates of different areas are equal to the linear combinations of the affine process $X_{t}$. This implies the existence of closed-form formulas to derive the conditional distribution functions of future inflation rates for any maturity (see Duffie, Pan, and Singleton (2000)). Specifically, we have:

$$
\mathbb{P}\left(\gamma_{1}^{\prime} X_{t+1}+\cdots+\gamma_{h}^{\prime} X_{t+h}<y \mid \underline{X_{t}}\right)=\frac{1}{2}-\frac{1}{\pi} \int_{0}^{\infty} \frac{\operatorname{Im}\left[\Psi_{h}\left(i v \gamma, X_{t}\right)\right] e^{-i v y}}{v} d v,
$$

where $\operatorname{Im}(c)$ denotes the imaginary part of $c \in \mathbb{C}$ and where $\Psi_{h}$ is the multi-horizon Laplace transform of $X_{t}$, defined by:

$$
\Psi_{h}\left(\mathbf{u}, X_{t}\right)=\mathbb{E}\left(\exp \left(u_{1}^{\prime} X_{t+1}+\cdots+u_{h}^{\prime} X_{t+h}\right) \mid \underline{X_{t}}\right),
$$

with $\mathbf{u}=\left[u_{1}, \ldots, u_{h}\right]$. A simple computation of the latter Laplace transform is provided by Lemma 7.2 in Appendix 7.1.1.

\subsection{Survey data}

\subsubsection{U.S. surveys}

U.S. surveys used in our study include the Survey of Professional Forecasters published by the Federal Reserve Bank of Philadelphia (US-SPF), Blue Chip Financial Forecasts (BCFF) and Blue Chip Economic Indicators (BCEI) surveys, the Survey of Primary Dealers (SPD) published by the Federal Reserve Bank of New York and the Consensus Economics Survey (CES), produced by Consensus Economics. Below we provide a brief description of each of them. Panel A of Table 1 summarizes the data set described below.

The US-SPF survey is conducted quarterly and provides forecasts on a wide range of macroeconomic and financial variables since 1968:Q4. ${ }^{39}$ For the purpose of this study, we use several inflation forecasts from the US-SPF.

First, we use density forecasts - available in the form of histograms - for the price change in the GDP price deflator (survey variable PRPGDP) for the current and the following calendar year, Y0 and Y1, respectively. ${ }^{40}$ US-SPF defines a price

\footnotetext{
${ }^{39}$ The US-SPF survey was formerly conducted by the American Statistical Association (ASA) and the National Bureau of Economic Research (NBER) and was taken over by the Philadelphia Fed in 1990:Q2.

${ }^{40}$ US-SPF started providing density projections of the core Consumer Price Index (survey variable PRCCPI) and of the core Personal Consumer Expenditures Index (survey variable PRCPCE) only in 2007:Q1. Therefore we concentrate on the density projections of the GDP price deflator (despite small level differences with the headline CPI index) in order to have information about the second moments of the future U.S. inflation rates starting from the beginning of our sample, 1999:Q1. US-SPF does not provide any density projections about headline CPI inflation.
} 
change as the annual-average over annual-average percent change in the level of the GDP price index that is available quarterly. The US-SPF inflation measure is well approximated by the following inflation target:

$$
\frac{1}{4}\left(\pi_{t+h-21, t+h-9}+\pi_{t+h-18, t+h-6}+\pi_{t+h-15, t+h-3}+\pi_{t+h-12, t+h}\right),
$$

where $h$ is the forecast horizon measured in months. The density functions are available both on an individual and aggregate basis but we use information from aggregated (averaged) forecast density functions. We use these density projections to obtain a survey-based inflation forecast uncertainty measure using the variance of the average density function. ${ }^{41}$ Forecast density functions are fixed event forecasts (namely for the current and the following years), therefore, the forecast horizon changes relatively to the survey's timing. We are able to construct the first and the second moments of density functions four, five, six, seven and eight quarters out. Our sample for the density functions is from 1999:Q1 to 2016:Q2. ${ }^{42}$

Second, we use the US-SPF five-year average headline CPI inflation consensus forecasts (survey variable CPI5YR) in order to identify more distant-horizon inflation forecasts. This projection is defined as the annual average inflation rate over the next five years. The "next five years" includes the year in which the survey is conducted and the following four years. This average inflation forecast corresponds to Y0-Y4 in our notations and is consistent with the following definition, at time $t$ :

$$
\frac{1}{5}\left(\pi_{t-12, t}+\pi_{t, t+12}+\pi_{t+12, t+24}+\pi_{t+24, t+36}+\pi_{t+36, t+48}\right) .
$$

Our sample for this variable spans from 2005:Q3 (its starting point in the US-SPF) to 2016:Q2.

The BCFF and BCEI surveys are published monthly. These surveys represent a reasonably stable panel of about 50 top professional analysts who forecast a range of financial (in the case of the BCFF) and macroeconomic (in the case of the BCEI) variables. The panels of the BCFF and BCEI analysts are different yet a lot of panel members participate in both surveys. ${ }^{43}$ Both Blue Chip surveys provide indi-

\footnotetext{
${ }^{41}$ In this study we abstract from heterogeneity issues associated with individual forecasters' inflation projections. Instead, for this and other surveys, we use aggregate histograms obtained by computing the averages of the individual forecasters' histograms. The aggregated histograms are then smoothed before computing associated variances (which we subsequently fit with our model). Appendix 7.6 provides details about the smoothing procedure. Information about the structure of the US-SPF survey and definitions of variables can be obtained in the spf-documentation.pdf file in https://www.philadelphiafed.org/research-and-data/ real-time-center/survey-of-professional-forecasters.

${ }^{42}$ The beginning of our sample is motivated by the onset of the euro-zone and availability of the euro-area surveys.

${ }^{43}$ For example, out of 47 and 53 participating analysts in the December 2015 BCFF and November 2015 BCEI surveys, respectively, 35 analysts were participating in both surveys.
} 
vidual point estimates of inflation forecasts, from which consensus and disagreement measures can be obtained. While Blue Chip inflation consensus forecasts have been used in the literature extensively (Chun, 2011; Chernov and Mueller, 2012; Grishchenko and Huang, 2013; D'Amico, Kim, and Wei, 2016; Grishchenko, Vanden, and Zhang, 2016), its inflation disagreement measures only recently became popular (Wright, 2011; Buraschi and Whelan, 2012; D'Amico and Orphanides, 2014; Shi, 2014). Monthly surveys provide inflation forecasts up to six quarters out. In addition to those, BCFF and BCEI surveys publish long-range forecasts twice a year. These long-range forecasts contain average annual forecasts usually five years out from the survey publication year and the average five-year forecast five years ahead (Y6-Y10 in our notations). We use Y6-Y10 consensus inflation forecasts in our model estimation.

The SPD survey started only in 2004 and, to the best of our knowledge, we are among the first to use this survey in the academic literature. ${ }^{44}$ The SPD survey nicely complements information from the US-SPF that provides density inflation forecasts for shorter horizons with those for longer horizons. Prior to each FOMC meeting, the survey asks primary dealers (currently 22) a number of questions including inflation density forecasts. The survey questions sometimes vary depending on the economic environment. ${ }^{45}$ Nonetheless, certain questions such as the density forecasts for the headline CPI inflation are routinely asked so the sufficient time series can already be gathered. In particular, since the FOMC meeting of March 2007, survey participants are asked to provide a percent chance attached to the five-year average annual CPI inflation five years ahead falling below 1\%, between $1.01 \%$ and $1.50 \%$, between $1.51 \%$ and $2 \%$, between $2.01 \%$ and $2.50 \%$, between $2.51 \%$ and $3 \%$ and above $3.01 \%{ }^{46}$ Since the FOMC meeting of December 2014, primary dealers are also asked to provide the same inflation density forecasts over the next five years. Thus, the Y6-Y10 density measure is available from 3/2007 until 6/2016 and the Y0-Y4 measure is available from 12/2014 to 6/2016.

As we mentioned above in section 7.4.1, the CES survey also provides inflation forecasts for a range of developed countries, on a monthly basis. The CES survey participants provide point estimates for the average annual percent change of the headline CPI index relative to the previous calendar year. These projections are available for the current and the next calendar years, Y0 and Y1 in our notations.

\footnotetext{
${ }^{44}$ Crump, Eusepi, and Moench (2016) use SPD to study nominal term premia.

${ }^{45}$ See posted questions on the website of the Federal Reserve Bank of New York: https://www . newyorkfed.org/markets/primarydealer_survey_questions.html.

${ }^{46}$ The bins did not change over the time of the survey.
} 


\subsubsection{Euro-area surveys}

Euro-area surveys include the Survey of Professional Forecasters published by the European Central Bank and the Consensus Economics Survey published by Consensus Economics. We briefly describe each of these two surveys below. Panel B of Table 1 summarizes these surveys.

The ECB-SPF survey was launched in the first quarter of 1999 and has received a amount of attention by academics and practitioners in recent years (see, e.g., Conflitti, 2011; Rich, Song, and Tracy, 2012; Andrade and Le Bihan, 2013). The survey provides GDP forecasts, inflation expectations and unemployment forecasts on a quarterly frequency. It also provides assumptions made by different forecasters. Up to date, the panel of forecasters includes 79 listed international and European institutions as well as a number of other participants who chose to remain anonymous. More than half of the survey participants involved in the first survey remain in the pool of participants today and the size of the survey panel remains about unchanged given that more than 20 new survey respondents were added throughout the years. The panel of veteran forecasters is thus relatively stable and the average number of panel members who answer all inflation-related questions across surveys remains stable and equals, on average, to 34. Participants are asked to provide point forecasts and probability distributions for rolling horizons (one and two years ahead year-onyear forecasts) and longer-term inflation expectations (five years ahead) implied by changes in the Harmonized Index of Consumer Prices (HICP). ECB-SPF inflation measures are defined as $\pi_{t+h-12, t+h}$, where $h$ is the forecast horizon measured in months.

The CES survey participants provide point estimates for the average annual percent change of HICP relative to the previous calendar year. These projections are available for the current and the next calendar year, since January 1999 (in the case of the euro area), on a monthly basis. There are roughly 20 institutions participating in the euro area survey; less than half of which coincide with disclosed ECB-SPF participants. Importantly, CES also publishes long-term forecasts on a semi-annual basis (i.e. in April and October), in which five-year five years ahead (Y6-Y10) inflation projections are available. We use these long-term forecasts to complement the ECB-SPF survey information.

\subsection{Survey-based uncertainty}

Measuring uncertainty has gained a lot of attention in recent years. Several proxies for uncertainty including stock market volatility, conditional volatility of series, cross-sectional dispersions and keyword counts in newspapers have been used. However, survey-based measures of uncertainty, also known as subjective measures of 
uncertainty, have become increasingly popular due to their model-free nature.

Three survey-based uncertainty measures have dominated the literature: i) the disagreement among forecasters (ex-ante measure), ii) the variance of the surveys' aggregate probability distribution (ex-ante measure) and iii) the average individual forecast error variance (ex-post measure). Ex-ante measures of uncertainty have been found to be more adequate representations of uncertainty in real time.

In this subsection we shall provide a brief account of the survey-based uncertainty literature.

Due to its simplicity and availability, one of the most common survey-based uncertainty proxies in the literature is the disagreement of forecasters defined as follows:

$$
d_{t h}=\frac{1}{N} \sum_{i=1}^{N}\left(f_{i t h}-f_{. t h}\right)^{2},
$$

where $N$ is the number of forecasters, $f_{i t h}$ is the forecast at time $t$, for horizon $h$ of individual $i$ and $f_{\text {.th }}$ is the mean forecast (i.e. consensus). This proxy of uncertainty, though easily computable, becomes irrelevant if heterogeneity in forecasters vanishes.

An important strand of the literature studies survey-based measured of disagreement and uncertainty (Conflitti, 2011; Rich, Song, and Tracy, 2012; Andrade and Le Bihan, 2013; Boero, Smith, and Wallis, 2014; D'Amico and Orphanides, 2014). Notably, Giordani and Soderlind (2003) find that disagreement is a fairly good proxy for other measures of uncertainty that are more theoretically appealing, but less easily available. ${ }^{47}$ Lahiri and Sheng (2010) decompose forecast errors into common and idiosyncratic shocks and show that aggregate forecast uncertainty can be expressed as the sum of the disagreement among forecasters and the perceived variability of future aggregate shocks. This finding implies that the reliability of disagreement as a proxy for uncertainty depends primarily on the stability of the forecasting environment.

As we mentioned in sections 7.4.1 and 7.4.2, the US-SPF, the SPD, and the ECB-SPF provide probability distributions at a forecaster level. The observed heterogeneity of forecasters is usually addressed by averaging the available individual distributions in a particular survey. This aggregation inherently implies the assumption of a representative forecaster. Uncertainty can now be defined as the variance of the aggregate probability distribution. One important implication is that the conditional variance of the aggregate distribution becomes the sum of disagreement and of the average of individual variances (which results from the application of the law of total variance). Thus, denoting by $\sigma_{a g g, t h}^{2}$ and $\sigma_{i t h}^{2}$ the conditional variance of

\footnotetext{
${ }^{47}$ According to their paper, previous research on SPF data implies a weak correlation between disagreement and other measures of uncertainty possibly due to: the failure in using a long enough sample and the failure in fitting a normal distribution to each histogram for obtaining a robust measure of disagreement.
} 
the aggregate distribution and the individual variances, respectively, the proxy for uncertainty is given by:

$$
\sigma_{a g g, t h}^{2}=d_{t h}+\frac{1}{N} \sum_{i=1}^{N} \sigma_{i t h}^{2} .
$$

This measure of uncertainty captures both forecasters' heterogeneity via the cross-sectional variance of individual means (i.e. disagreement) and the average uncertainty of individual forecasters. In this paper, we thus draw our attention to this particular survey-based uncertainty measure.

\subsection{Smoothing survey-based and risk-neutral distributions}

\subsubsection{Overview}

Our analysis makes use of the generalised beta distribution twice. First, we use it in order to convert the forecasters' views about the probabilities of future inflation outcomes; this information being available in the form of histograms in some surveys (see Appendix 7.4). Second, the generalised beta distribution is used to convert inflation option prices into risk-neutral distributions. While the former distributions are essential in the estimation of our model, the latter are used after the estimation, when we study our model outputs.

In both cases, the spirit of the smoothing methodology, that broadly builds on Engelberg, Manski, and Williams (2009) (see also Boero, Smith, and Wallis, 2014; Clements, 2014), is the same. We consider the data associated with a specific inflation distribution, as defined by: (a) one area, (b) one measure of inflation (yearon-year growth rate of the price index, annualised growth rate over a given period or average of year-on-year growth rates), (c) one horizon and (d) a given type of probability measure (historical in the first case, risk-neutral in the second case). Then, we assume that these data are coherent with a generalised Beta distribution and look for the parametrisation of this distribution that provides the closest fit to the considered data (by minimising the sum of weighted squared deviations between the data and its theoretical counterpart).

In the first case, the data consists of survey-based probabilities of future inflation outcomes falling within given ranges (see Appendix 7.4). These survey-based data provide us with evaluations of the cumulative distribution function (c.d.f.) of the associated distribution at the right-hand bounds of the bins (excluding the last bin, which usually is of the form $[\gamma, \infty$ [, where $\gamma$ is the right-hand bound of the penultimate bin). Let us stress that these smoothed distributions are fundamentally different from those resulting from the approach developed in the present paper. Indeed, the latter are coherent across time and horizons, which is not the case of the 
former. Heuristically, the smoothing approach presented in this appendix constitutes a preliminary processing of the data before using them in the model estimation.

In the second case, the data consists of market quotes of inflation derivatives, namely inflation floors and swaps. As explained in Subsection 7.6.3, these market quotes closely relate to the forward-neutral distribution of inflation, which is a probability measure that is equivalent to the physical one. As soon as one observes a sufficiently large number of inflation derivatives' quotes, one can estimate the generalised Beta distribution that provides the closest set of "theoretical" quotes. For each considered horizon and date, we use six market quotes to estimate the forwardneutral distribution: five prices of inflation floors (with strikes of $-2 \%,-1 \%, 0 \%$, $1 \%$ and $-2 \%$ ) and the inflation swap rate.

\subsubsection{Generalised Beta distribution}

$X$ is distributed as a generalised Beta distribution of parameters $(a, b, c, d)$ if $(X-$ $c) /(d-c)$ is distributed as $B(a, b)$. In that case, we use the following notation: $X \sim \mathcal{B}(a, b, c, d)$. If $X \sim \mathcal{B}(a, b, c, d)$, we have $\mathbb{P}(X<x)=\mathbb{P}(Y<(x-c) /(d-c))$, where $Y$ is distributed as $B(a, b)$. Therefore, the c.d.f. of $X$ is:

$$
F(x)=\frac{\operatorname{Bet} a((x-c) /(d-c) ; a, b)}{B(a, b)}
$$

where $\operatorname{Bet} a(x ; a, b)$ is the incomplete Beta function, defined by:

$$
\operatorname{Beta}(x ; a, b):=\int_{0}^{x} t^{a-1}(1-t)^{b-1} d t .
$$

The distribution function of $X$ then is:

$$
f(x ; a, b, c, d):=\mathbb{I}_{\{x \in[c, d]\}} \frac{1}{(d-c) B(a, b)}\left(\frac{x-c}{d-c}\right)^{a-1}\left(\frac{d-x}{d-c}\right)^{b-1} .
$$

\subsubsection{T-forward-neutral distribution of inflation}

Denoting by $f_{t}^{T-t}$ the $T$-forward-neutral distribution of the inflation rate $\pi_{t, T}$, the price of a zero-coupon inflation floor, as of date $t$, with an exercise rate of $S$ and an expiry date $t+h$ is given by:

$$
\begin{aligned}
\operatorname{floor}_{t, h}(S) & =e^{-h r_{t, h}} \int_{-\infty}^{S}\left\{(1+x)^{h}-(1+S)^{h}\right\} f_{t}^{h}(x) d x \\
& \approx h e^{-h r_{t, h}} \int_{-\infty}^{S}(S-x) f_{t}^{h}(x ; a, b, c, d) d x
\end{aligned}
$$

where $r_{t, h}$ is the risk-free interest rate between dates $t$ and $t+h$ (known at date $t$ ). 
Let us assume that the $T$-forward neutral distribution of $\pi_{t, t+h}$ is $\mathcal{B}(a, b, c, d)$. In that case, the price of the previous floor is approximately equal to:

$$
\begin{aligned}
& e^{-h r_{t, h} h} \int_{c}^{S}(S-x) \frac{1}{(d-c) B(a, b)}\left(\frac{x-c}{d-c}\right)^{a-1}\left(\frac{d-x}{d-c}\right)^{b-1} d x \\
= & e^{-h r_{t, h}} h(d-c) \int_{0}^{\frac{S-c}{d-c}}\left(\frac{S-c}{d-c}-y\right) \frac{1}{B(a, b)} y^{a-1}(1-y)^{b-1} d y \\
= & e^{-h r_{t, h}} h(d-c) \frac{S-c}{d-c} \int_{0}^{\frac{S-c}{d-c}} \frac{1}{B(a, b)} y^{a-1}(1-y)^{b-1} d y- \\
= & \frac{e^{-h r_{t, h}} h(d-c) \int_{0}^{\frac{S-c}{d-c}} \frac{1}{B(a, b)} y^{a}(1-y)^{b-1} d y}{B(a, b)} \times \\
& \left\{(S-c) \operatorname{Beta}\left(\frac{S-c}{d-c} ; a, b\right)-(d-c) \operatorname{Beta}\left(\frac{S-c}{d-c} ; a+1, b\right)\right\}
\end{aligned}
$$

Moreover, in that context, the inflation swap rate of maturity $h$, denoted by $s_{t, t+h}$ is such that

$$
\int_{-\infty}^{+\infty}\left\{(1+x)^{h}-(1+S)^{h}\right\} f_{t}^{h}(x) d x=0
$$

which implies that:

$$
s_{t, t+h} \approx \int_{c}^{d} x f_{t}^{h}(x) d x=\frac{b c+a d}{a+b}
$$


Table 1: Summary of the surveys data

\begin{tabular}{|c|c|c|c|c|c|c|}
\hline Survey & Horizon & Description & \multicolumn{2}{|l|}{ Inflation Rate Def } & Freq. & Sample \\
\hline \multicolumn{7}{|c|}{ Panel A: U.S. surveys of inflation forecasts } \\
\hline US SPF & Y0 & Density & $\begin{array}{l}\text { Annual-avg } \\
\text { annual-avg }\end{array}$ & over & $\mathrm{Q}$ & 1999:Q1 - 2016:Q2 \\
\hline US SPF & Y1 & Density & $\begin{array}{l}\text { Annual-avg } \\
\text { annual-avg }\end{array}$ & over & $\mathrm{Q}$ & 1999:Q1 - 2016:Q2 \\
\hline US SPF & Y0-Y4 & P.E. & Q4 over Q4 & & $\mathrm{Q}$ & 2005:Q3 - 2016:Q2 \\
\hline BCFF \& BCEI & Y6-Y10 & P.E. & Annual average & & 4/year & $3 / 1999-6 / 2016$ \\
\hline SPD & Y0-Y4 & Density & Annual average & & 8/year & $12 / 2014-6 / 2016$ \\
\hline SPD & Y6-Y10 & Density & Annual average & & $8 /$ year & $3 / 2007-6 / 2016$ \\
\hline CES & Y0 & P.E. & Annual average & & M & $1 / 1999-6 / 2016$ \\
\hline CES & Y1 & P.E. & Annual average & & M & $1 / 1999-6 / 2016$ \\
\hline \multicolumn{7}{|c|}{ Panel B: Euro-area surveys of inflation forecasts } \\
\hline ECB SPF & Y1 & Density & Annual inflation & & Q & $1 / 1999-6 / 2016$ \\
\hline ECB SPF & Y1-Y2 & Density & Annual inflation & & Q & $1 / 1999-6 / 2016$ \\
\hline ECB SPF & Y4-Y5 & Density & Annual inflation & & Q & $1 / 1999-6 / 2016$ \\
\hline CES & Y6-Y10 & P.E. & Annual average & & $\mathrm{SA}$ & $4 / 2003-4 / 2016$ \\
\hline
\end{tabular}

This table summarizes inflation forecast variables from the U.S. and euro-area surveys used in the study. Column 1 specifies the surveys: US SPF (Survey of Professional Forecasters conducted by the Federal Reserve Bank of Philadelphia), BCFF and BCEI (Blue Chip Financial Forecasts and Economic Indicators surveys), SPD (Survey of Primary Dealers conducted by the Federal Reserve Bank of New York), CES (Consensus Economics Survey, produced by Consensus Economics), ECB SPF (Survey of Professional Forecasters conducted by the European Central Bank). Column 2 specifies the horizon of the inflation forecast: Y0 - current year, Y1 - next year, Y0-Y4 - 5-year horizon and so on. Column 3 specifies whether point estimates (P.E.) of the forecasts or the first two moments of the reported density projections (density) are used in the model estimation. Column 4 provides a definition of the inflation rate forecast reported in surveys. Column 5 specifies the available frequency of the forecasts and Column 6 - the sample period used in the estimation. All U.S. inflation forecasts are on headline Consumer Price Index (CPI) index except the density projections from the US-SPF, which are on the annual GDP price inflation. All euro-area inflation forecasts are on the Harmonized Index of Consumer Prices (HICP). 
Table 2: Determination of the number of latent factors

\begin{tabular}{|c|c|c|c|c|c|c|c|c|c|c|c|c|}
\hline \multicolumn{13}{|c|}{ Panel A: PCA on residuals } \\
\hline PC1 & $\mathrm{PC} 2$ & PC3 & $\mathrm{PC} 4$ & PC5 & PC6 & $\mathrm{PC} 7$ & PC8 & PC9 & PC10 & PC11 & PC12 & \\
\hline 74.96 & 93.24 & 97.60 & 98.72 & 99.60 & 99.75 & 99.87 & 99.93 & 99.96 & 99.98 & 100.00 & 100.00 & \\
\hline \multicolumn{13}{|c|}{ Panel B: $R^{2}$ coefficients of regressions } \\
\hline$\overline{\mathrm{EA}} 1 \mathrm{Y}$ & EA $2 Y$ & EA $3 Y$ & EA $5 Y$ & EA $7 \mathrm{Y}$ & EA $10 Y$ & US $1 Y$ & US $2 \mathrm{Y}$ & US $3 \mathrm{Y}$ & US $5 \mathrm{Y}$ & US $7 \mathrm{Y}$ & US $10 Y$ & Mean \\
\hline 95.62 & 98.14 & 99.04 & 99.10 & 98.67 & 96.96 & 97.81 & 98.98 & 98.22 & 94.44 & 90.87 & 83.11 & 95.91 \\
\hline \multicolumn{13}{|c|}{ Panel C: Joint PCA on market-based variances } \\
\hline $\mathrm{PC} 1$ & $\mathrm{PC} 2$ & PC3 & $\mathrm{PC} 4$ & PC5 & PC6 & $\mathrm{PC} 7$ & PC8 & PC9 & PC10 & PC11 & $\mathrm{PC} 12$ & \\
\hline 79.97 & 90.17 & 93.39 & 95.41 & 96.51 & 97.28 & 98.01 & 98.61 & 99.19 & 99.57 & 99.88 & 100.00 & \\
\hline
\end{tabular}

This table summarises the results of our analysis to determine the number of latent factors in our estimation. Panel A summarizes the results of a principal component analysis on residuals stemming from bivariate regressions of area-specific inflation swaps on area-specific realised inflation series. The cumulative percentage of cross-sectional variation accounted for by each component is displayed. Panel B reports the $R^{2}$ coefficients stemming from regressions of inflation swaps on realised inflation series of the two economies and on the two first principal components of Panel A. Panel C displays the results of a principal component analysis on risk-neutral variances estimated on inflation floors contracts. Reported figures are expressed in percentage points. Area-specific inflation swaps and market-based variances consist of six different maturities, namely 1, 2, 3, 5, 7 and 10 years. Refer to Appendix 7.6 for further details. 
Table 3: Parameter estimates

\begin{tabular}{|c|c|c|c|c|c|c|c|}
\hline & Adjust. & Value & St.dev. & & Adjust. & Value & St.dev. \\
\hline $\bar{\pi}^{(1)}$ & & 1.796 & - & $\Theta_{1,1}$ & $\left(\times 10^{3}\right)$ & 0.441 & 0.401 \\
\hline \multirow[t]{2}{*}{$\bar{\pi}^{(2)}$} & & 2.402 & - & $\Theta_{2,1}$ & $\left(\times 10^{3}\right)$ & -1.624 & 1.087 \\
\hline & & & & $\Theta_{3,1}$ & $\left(\times 10^{3}\right)$ & -1.615 & 0.657 \\
\hline$\delta_{1}^{(1)}$ & & 1.000 & - & $\Theta_{4,1}$ & $\left(\times 10^{3}\right)$ & -0.971 & 0.428 \\
\hline$\delta_{2}^{(1)}$ & & 0.282 & 0.053 & $\Theta_{1,2}$ & $\left(\times 10^{3}\right)$ & 0.083 & 0.085 \\
\hline$\delta_{3}^{(1)}$ & & 1.000 & - & $\Theta_{2,2}$ & $\left(\times 10^{3}\right)$ & -2.304 & 1.066 \\
\hline$\delta_{4}^{(1)}$ & & 0.146 & 0.067 & $\Theta_{3,2}$ & $\left(\times 10^{3}\right)$ & -0.090 & 0.311 \\
\hline$\delta_{1}^{(2)}$ & & 1.154 & 0.576 & $\Theta_{4,2}$ & $\left(\times 10^{3}\right)$ & -0.362 & 0.212 \\
\hline$\delta_{2}^{(2)}$ & & 1.000 & - & & & & \\
\hline$\delta_{3}^{(2)}$ & & 0.577 & 0.112 & $\Gamma_{Y, 0[1]}$ & $\left(\times 10^{3}\right)$ & 3.530 & 5.543 \\
\hline \multirow{2}{*}{$\delta_{4}^{(2)}$} & & 1.000 & - & $\Gamma_{Y, 0[2]}$ & $\left(\times 10^{3}\right)$ & 24.743 & 54.667 \\
\hline & & & & $\Gamma_{Y, 0[3]}$ & $\left(\times 10^{3}\right)$ & 15.234 & 11.574 \\
\hline$\Phi_{Y[1,1]}$ & & 0.983 & 0.004 & $\Gamma_{Y, 0[4]}$ & $\left(\times 10^{3}\right)$ & 1.890 & 19.526 \\
\hline$\Phi_{Y[2,1]}$ & & 0.004 & 0.192 & & & & \\
\hline$\Phi_{Y[3,1]}$ & & -0.002 & 0.074 & $\Gamma_{Y, 1[1,1]}$ & $\left(\times 10^{3}\right)$ & 0.008 & 0.065 \\
\hline$\Phi_{Y[4,1]}$ & & -0.034 & 0.049 & $\Gamma_{Y, 1[2,1]}$ & $\left(\times 10^{3}\right)$ & 0.000 & 0.019 \\
\hline$\Phi_{Y[2,2]}$ & & 0.714 & 0.039 & $\Gamma_{Y, 1[3,1]}$ & $\left(\times 10^{3}\right)$ & 0.209 & 1.140 \\
\hline$\Phi_{Y[3,2]}$ & & 0.005 & 0.031 & $\Gamma_{Y, 1[4,1]}$ & $\left(\times 10^{3}\right)$ & 1.154 & 0.585 \\
\hline$\Phi_{Y[4,2]}$ & & -0.090 & 0.027 & $\Gamma_{Y, 1[1,2]}$ & $\left(\times 10^{3}\right)$ & 1.184 & 0.317 \\
\hline$\Phi_{Y[3,3]}$ & & 0.891 & 0.013 & $\Gamma_{Y, 1[2,2]}$ & $\left(\times 10^{3}\right)$ & 0.182 & 0.087 \\
\hline$\Phi_{Y[4,3]}$ & & 0.001 & 0.011 & $\Gamma_{Y, 1[3,2]}$ & $\left(\times 10^{3}\right)$ & 0.424 & 0.339 \\
\hline$\Phi_{Y[4,4]}$ & & 0.934 & 0.006 & $\Gamma_{Y, 1[4,2]}$ & $\left(\times 10^{3}\right)$ & 0.904 & 0.297 \\
\hline$\nu_{1}$ & & 0.073 & 0.043 & & & & \\
\hline$\nu_{2}$ & & 0.301 & 0.255 & & & & \\
\hline$\Phi_{z[1,1]}$ & & 0.991 & 0.002 & & & & \\
\hline$\Phi_{z[2,1]}$ & $\left(\times 10^{2}\right)$ & 0.000 & 0.043 & & & & \\
\hline$\Phi_{z[2,2]}$ & & 0.984 & 0.002 & & & & \\
\hline
\end{tabular}

The model is estimated by maximizing the quasi-likelihood stemming from a modified Kalman filter. Standard deviations (in italics) are calculated from the outer product of the log-likelihood gradient, evaluated at the estimated parameter values. For the sake of identification, different elements of $\delta$ are set to 1 . Superscripts in parentheses indicate the currency areas: 1 for the euro area and 2 for the US. 
Table 4: Euro-area and U.S. inflation: Deflation probabilities, co-movements and risk measures

\begin{tabular}{|c|c|c|c|c|c|c|c|c|c|c|}
\hline & $\underset{S}{E}$ & 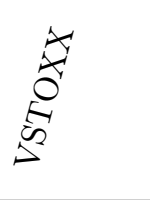 & $\begin{array}{c}\underset{A}{\Delta=1} \\
\text { S } \\
S\end{array}$ & 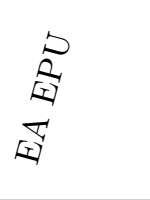 & $\underset{\underbrace{}}{\infty}$ & $\begin{array}{l}\circlearrowright \\
\Xi \\
\Xi\end{array}$ & 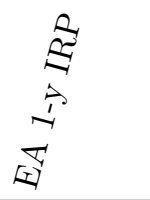 & 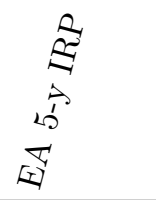 & $\underset{\frac{1}{s}}{\stackrel{a}{s}}$ & 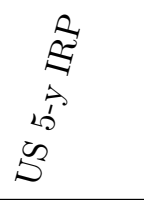 \\
\hline \multicolumn{11}{|l|}{ Panel A: Comovements } \\
\hline Joint Deflation Proba., 1-y & $(+) 2$ & $(+) 1$ & $(+) 1$ & $(+) 4^{*}$ & $(-) 17^{*}$ & $(-) 9$ & $(-) 12^{* *}$ & $(-) 10^{*}$ & $(-) 5^{*}$ & $(-) 9^{*}$ \\
\hline Joint Deflation Proba., 5-y & $(-) 3$ & $(-) 0$ & $(+) 9^{*}$ & $(+) 39^{* *}$ & $(-) 5$ & $(-) 7$ & $(-) 26^{* *}$ & $(-) 56^{* *}$ & $(-) 2$ & $(-) 4$ \\
\hline Inflation Covariance, 1-y & $(+) 7^{*}$ & $(+) 6$ & $(+) 18^{* *}$ & $(+) 19^{*}$ & $(-) 37^{* *}$ & $(-) 57^{* *}$ & $(-) 0$ & $(+) 0$ & $(-) 17^{* *}$ & $(-) 7^{*}$ \\
\hline Inflation Covariance, 5-y & $(-) 0$ & $(+) 0$ & $(+) 17^{* *}$ & $(+) 43^{* *}$ & $(-) 17^{* *}$ & $(-) 27^{* *}$ & $(-) 15^{*}$ & $(-) 29^{* *}$ & $(-) 6$ & $(-) 5$ \\
\hline \multicolumn{11}{|l|}{ Panel B: United States } \\
\hline U.S. Deflation proba., 1-y & $(+) 18^{*}$ & $(+) 12$ & $(+) 3$ & $(+) 0$ & $(-) 39^{*}$ & $(-) 22^{*}$ & $(-) 3$ & $(+) 0$ & $(-) 19^{* *}$ & $(-) 13^{* *}$ \\
\hline U.S. Deflation proba., 5-y & $(+) 0$ & $(+) 1$ & $(+) 16^{* *}$ & $(+) 40^{* *}$ & $(-) 17^{* *}$ & $(-) 25^{* *}$ & $(-) 17^{* *}$ & $(-) 31^{* *}$ & $(-) 9$ & $(-) 8$ \\
\hline U.S. Inflation variance, $1-\mathrm{y}$ & $(+) 21^{* *}$ & $(+) 12^{* *}$ & $(+) 1$ & $(-) 5$ & $(-) 16^{*}$ & $(-) 23^{* *}$ & $(+) 14$ & $(+) 46^{* *}$ & $(-) 9^{*}$ & $(-) 1$ \\
\hline U.S. Inflation variance, $5-\mathrm{y}$ & $(+) 11^{* *}$ & $(+) 9^{*}$ & $(+) 16^{* *}$ & $(+) 12$ & $(-) 39^{* *}$ & $(-) 59^{* *}$ & $(+) 0$ & $(+) 2$ & $(-) 18^{* *}$ & $(-) 6$ \\
\hline \multicolumn{11}{|l|}{ Panel C: Euro area } \\
\hline E.A. Deflation proba., 1-y & $(-) 0$ & $(+) 0$ & $(+) 1$ & $(+) 12^{* *}$ & $(-) 3$ & $(-) 1$ & $(-) 33^{* *}$ & $(-) 45^{* *}$ & $(-) 3$ & $(-) 10$ \\
\hline E.A. Deflation proba., $5-y$ & $(-) 2$ & $(-) 0$ & $(+) 10^{*}$ & $(+) 41^{* *}$ & $(-) 4$ & $(-) 6$ & $(-) 27^{* *}$ & $(-) 59^{* *}$ & $(-) 2$ & $(-) 4$ \\
\hline E.A. Inflation variance, $1-y$ & $(-) 0$ & $(+) 0$ & $(+) 17^{* *}$ & $(+) 42^{* *}$ & $(-) 18^{* *}$ & $(-) 28^{* *}$ & $(-) 14^{*}$ & $(-) 28^{* *}$ & $(-) 7$ & $(-) 5$ \\
\hline E.A. Inflation variance, 5-y & $(-) 1$ & $(-) 0$ & $(+) 14^{* *}$ & $(+) 44^{* *}$ & $(-) 11^{*}$ & $(-) 17^{*}$ & $(-) 20^{*}$ & $(-) 42^{* *}$ & $(-) 3$ & $(-) 4$ \\
\hline
\end{tabular}

This table reports synthetic results of bivariate regressions of the variables appearing on the first column of the table on those reported in the first row. The sign of the slope is in parentheses. Reported figures are regression $R^{2} \mathrm{~s}$, expressed in percentage points. *, ** and *** denote the statistical significance of the slope coefficient at the $10 \%, 5 \%$ and $1 \%$ level, respectively. Standard errors are HAC Newey-West (12 lag) corrected. The number of observations is 203. Variables' abbreviations are as follows: y - year; EC ES - European commission economic sentiment index; UM CS - University of Michigan survey of consumers sentiment index; EPU - economic policy uncertainty; IRP - inflation risk premium (computed as the spread between inflation swaps and model-implied inflation expectations with the horizon of the latter being equal to the maturity of the former). 
Figure 1: Factor loadings of expectations and variances of future inflation rates

Euro area, $Y$ loadings of conditional expectations

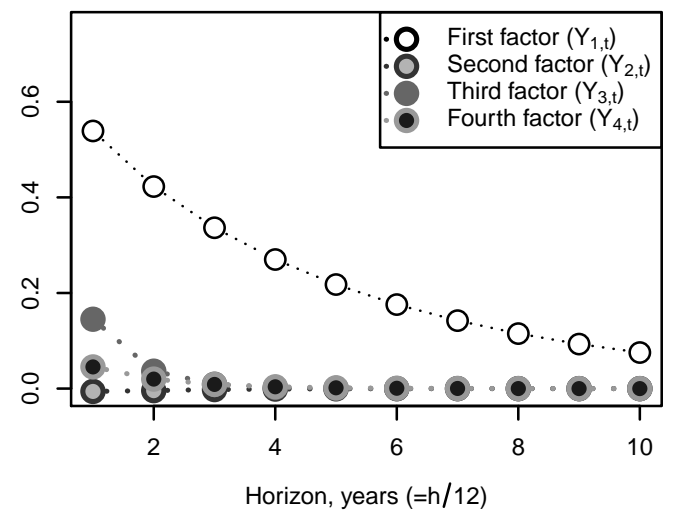

Euro area, $z$ loadings of conditional expectations

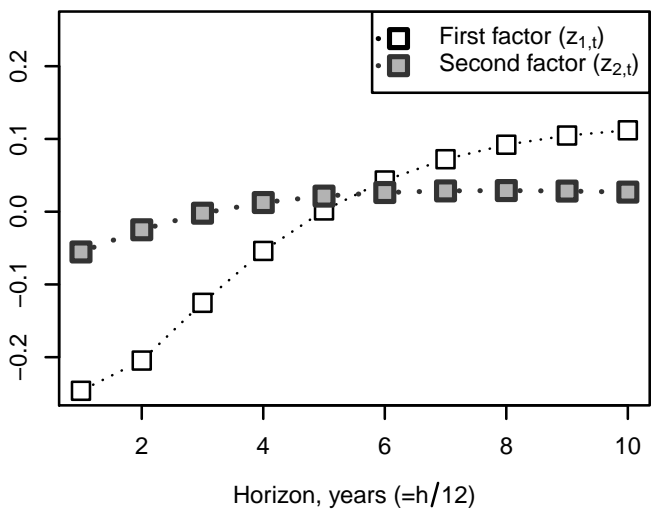

Euro area, $\mathrm{z}$ loadings of conditional variances

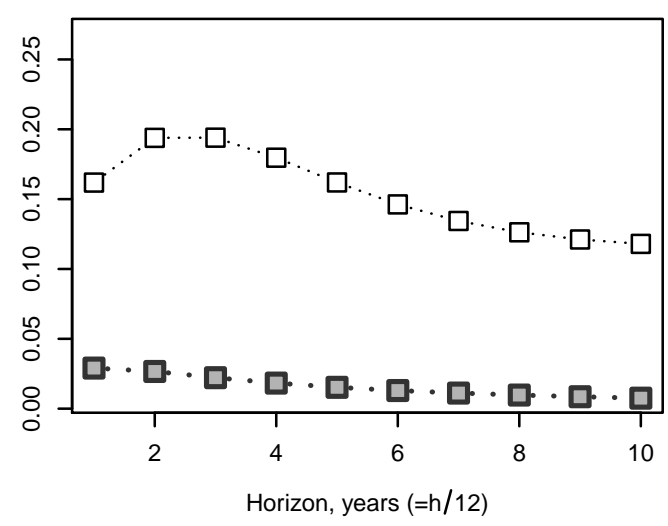

United States, Y loadings of conditional expectations

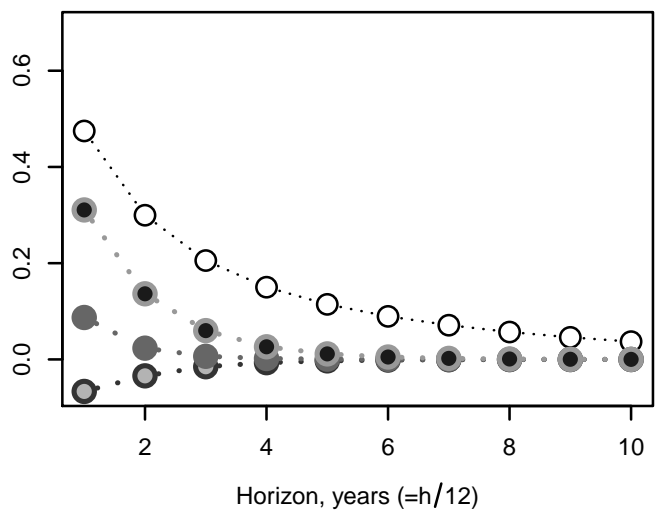

United States, $\mathrm{z}$ loadings of conditional expectations

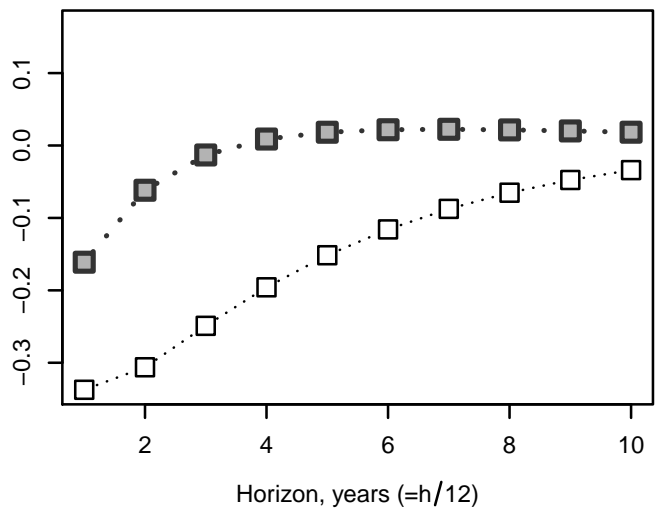

United States, $\mathbf{z}$ loadings of conditional variances

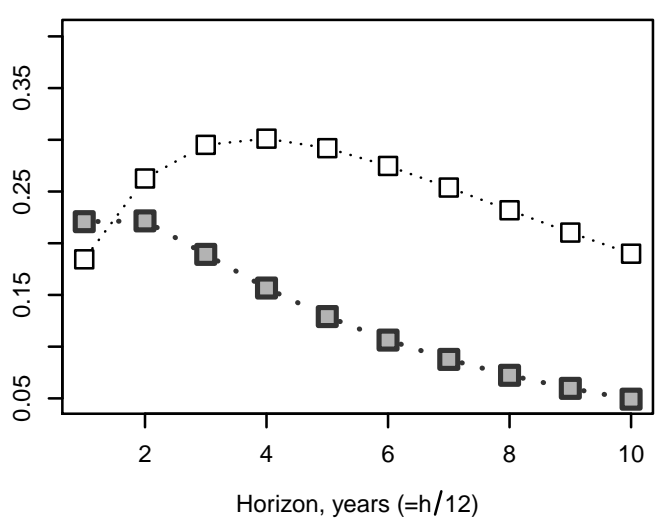

This figure displays, for different horizons $h / 12$ (where $h$ is measured in months), the entries of vectors $b_{h}^{(i)}$ and $\beta_{h}^{(i)}$ appearing in eqs. (9) and (10). In order to facilitate interpretation, these loadings have been multiplied by the marginal standard deviations of the associated factors. That is, the $y$-coordinates correspond to the effect of a one-standard deviation change in the factors on the conditional level of inflation expectations (or variances for the bottom charts). 
Figure 2: Fit of inflation and survey data

Euro area
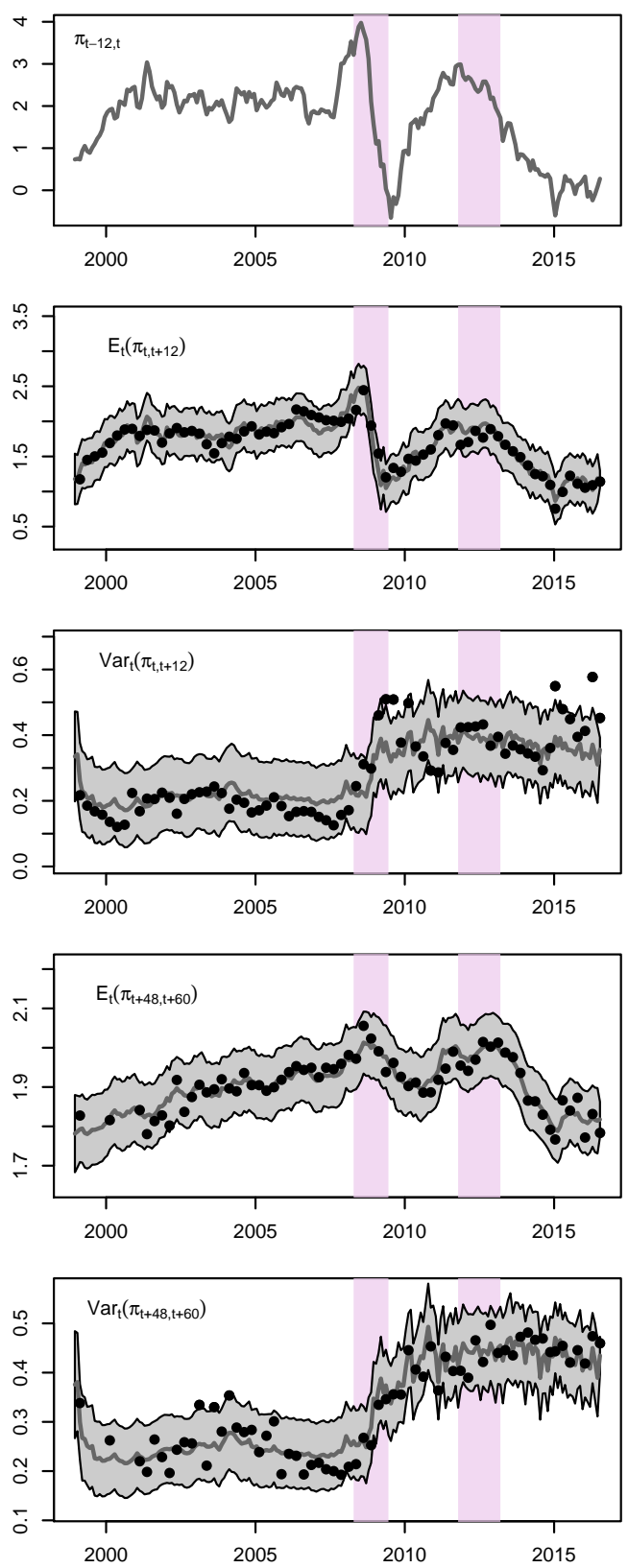

United States
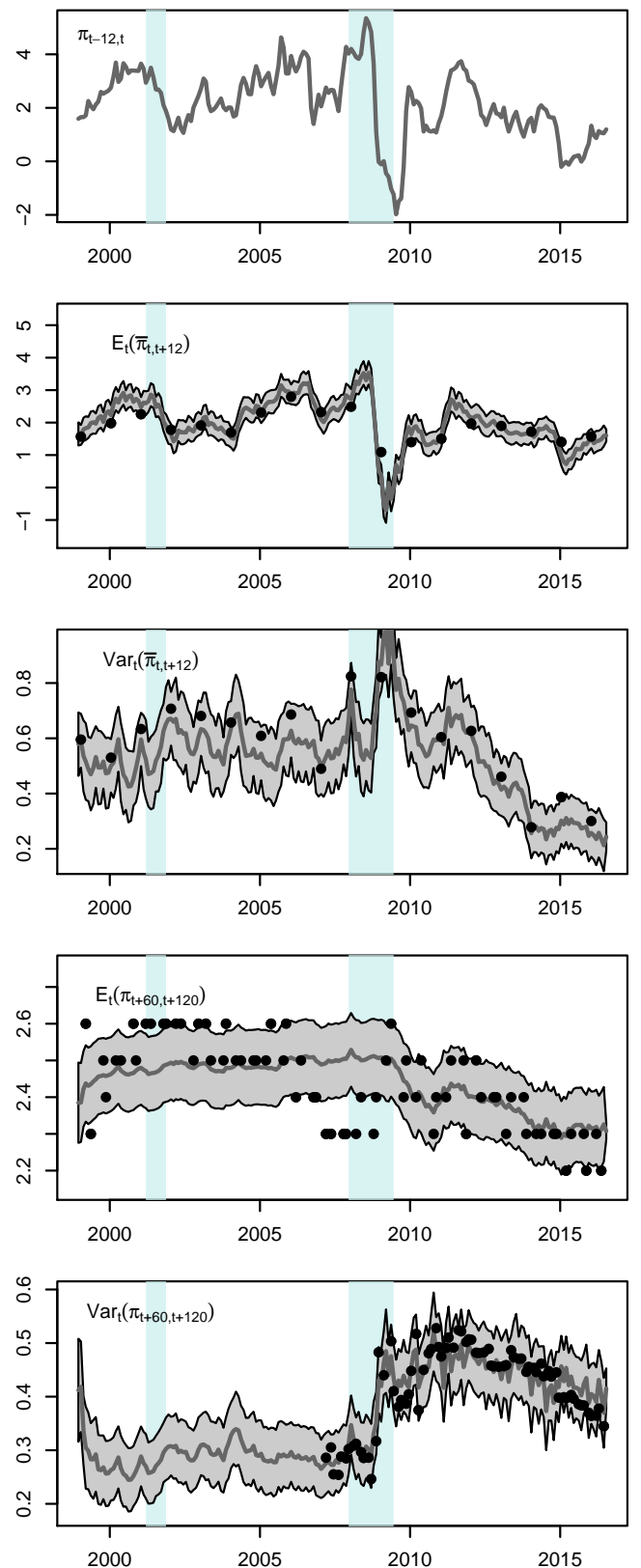

This figure illustrates the fitting properties of the model. The top charts plot realized inflation rates, based on HICP (in the case of the euro area) and headline CPI (in the case of the U.S.). The dots on the charts at the left-hand side (euro-area results) correspond to the observations available in the ECB-SPF survey. The dots on the charts at the right hand side (U.S. results) are taken from several U.S. surveys: the dots on the $E_{t}\left(\bar{\pi}_{t+12}\right)$ and $\operatorname{Var}_{t}\left(\bar{\pi}_{t+12}\right)$ charts are taken from the US-SPF survey, the dots on the $E_{t}\left(\bar{\pi}_{t+60, t+120}\right)$ chart are taken from the long-range BCFF and BCEI surveys, the dots on the $\operatorname{Var}_{t}\left(\bar{\pi}_{t+60, t+120}\right)$ chart are from the SPD survey. The grey-shaded areas are the calibrated 2-standard-deviation confidence intervals. For the sake of readability, this figure does not show the fit of all observed surveys. For U.S. charts, the notation $\bar{\pi}_{t+h}$ refers to the US-SPF inflation measure, which is the annual-quarter-average over annual-quarter-average percent change in prices (see Appendix 7.4.1 for details.) Here and on the following charts, pink bars indicate euro-area CEPR recessions and blue bars indicate U.S. NBER recessions. 


\section{Figure 3: Fit of survey distributions}

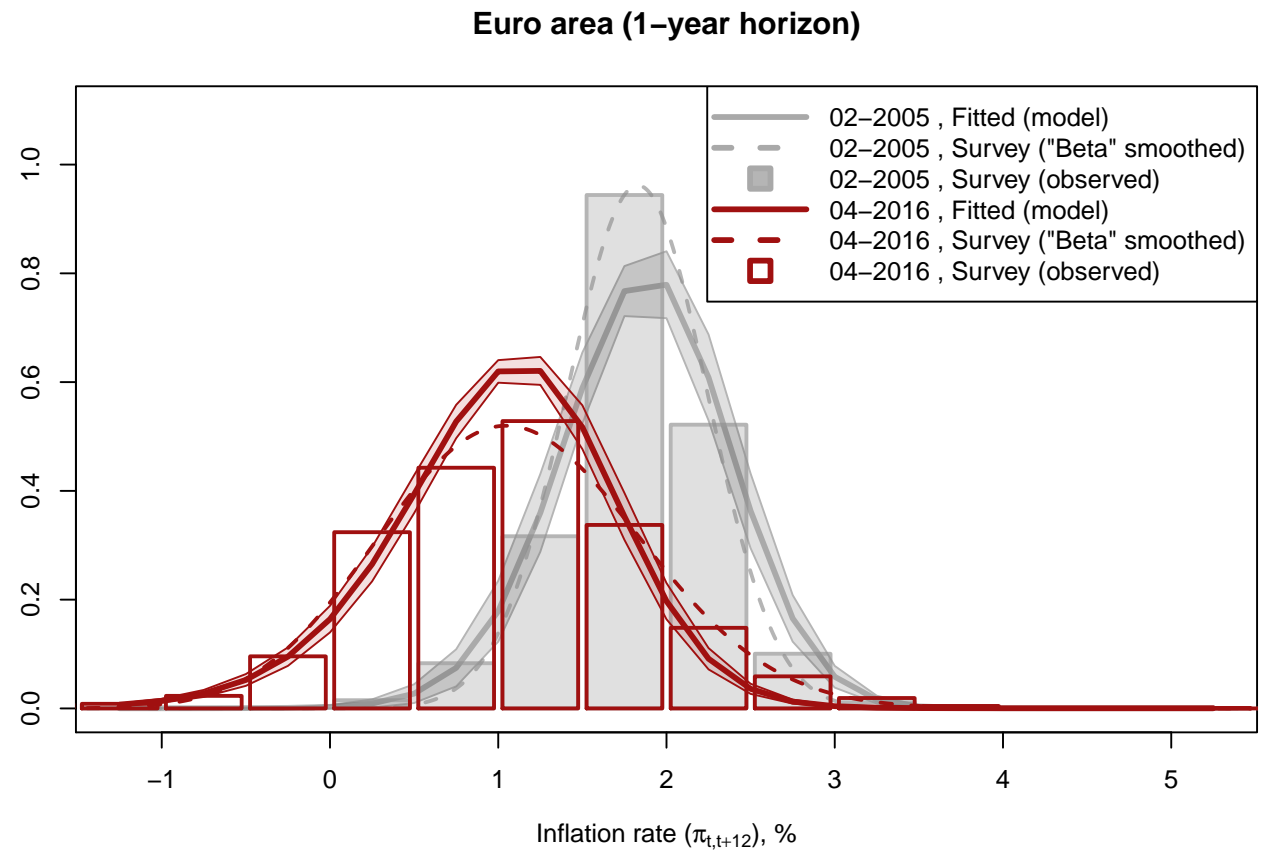

United States (1-year horizon)

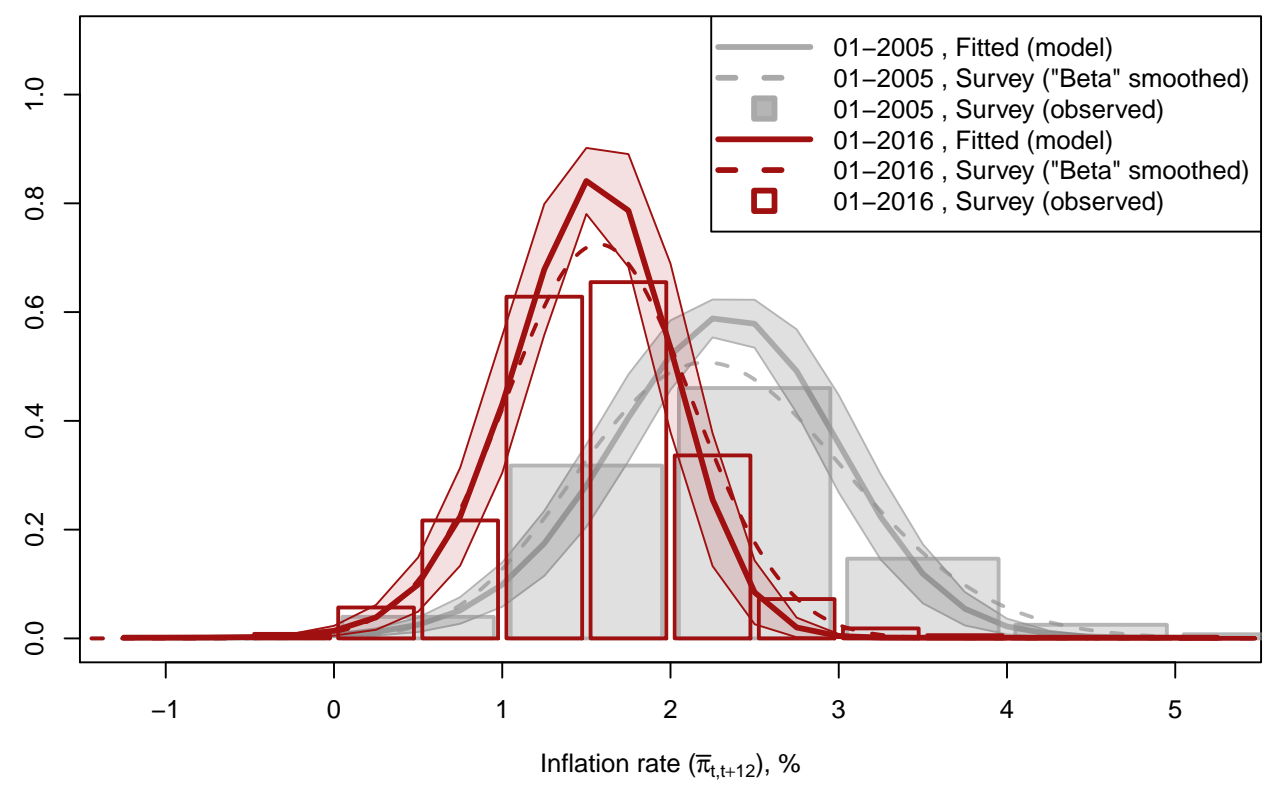

This figure compares the one-year ahead survey-based histograms (ECB SPF and US SPF, see Table 1) to their smoothed counterparts (see Appendix 7.6) and to the one-year ahead model-implied distributions. For the model-implied distributions, two-standard-deviation confidence intervals are reported. These standard deviations reflect uncertainty associated with the estimation of the latent factors $X_{t}$. These standard deviations are obtained by applying the delta method on the function relating factors $X_{t}$ to the conditional cumulative distribution function (c.d.f.) of future inflation (see Appendix 7.3). (In the context of the delta method, the covariance matrix of the smoothed values of $X_{t}$ - these smoothed values being defined by $\mathbb{E}\left(X_{t} \mid \underline{S_{T}}\right)$, where $T$ is the length of our sample stems from the Kalman smoothing algorithm (Harvey, 1989).) 


\section{Figure 4: Term structure of inflation expectations}

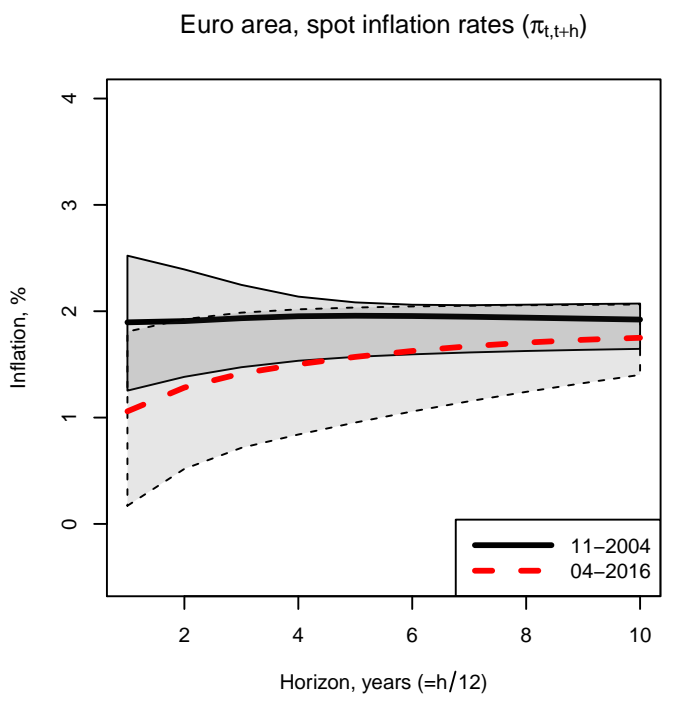

Euro area, forward inflation rates $\left(\pi_{\mathrm{t}+\mathrm{h}-12, \mathrm{t}+\mathrm{h}}\right)$

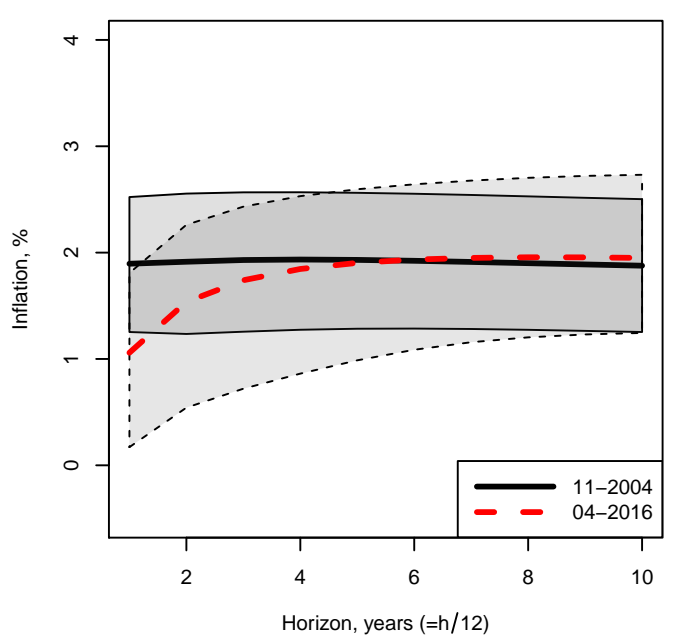

United States, spot inflation rates $\left(\pi_{\mathrm{t}, \mathrm{t}+\mathrm{h}}\right)$

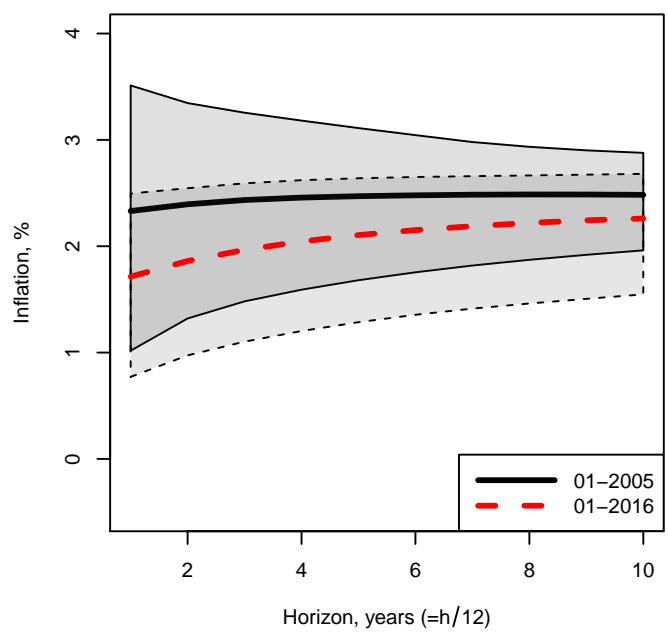

United States, forward inflation rates $\left(\pi_{\mathrm{t}+\mathrm{h}-12, \mathrm{t}+\mathrm{h}}\right)$

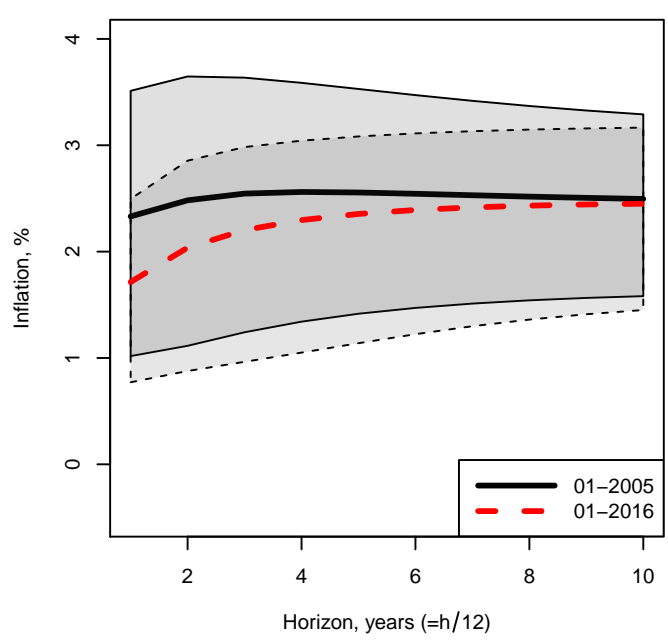

This figure displays the term structure of model-implied expected inflation rates along with the 5th and 95th quantiles associated with the respective conditional distributions. The top two (bottom two) panels display spot inflation (one-year ahead forward inflation) rates up to a horizon of 10 years in the euro area and the Untied States. The quantiles are derived from the closed-form formulas given in Appendix 7.3. 
Figure 5: Term structure of inflation uncertainty
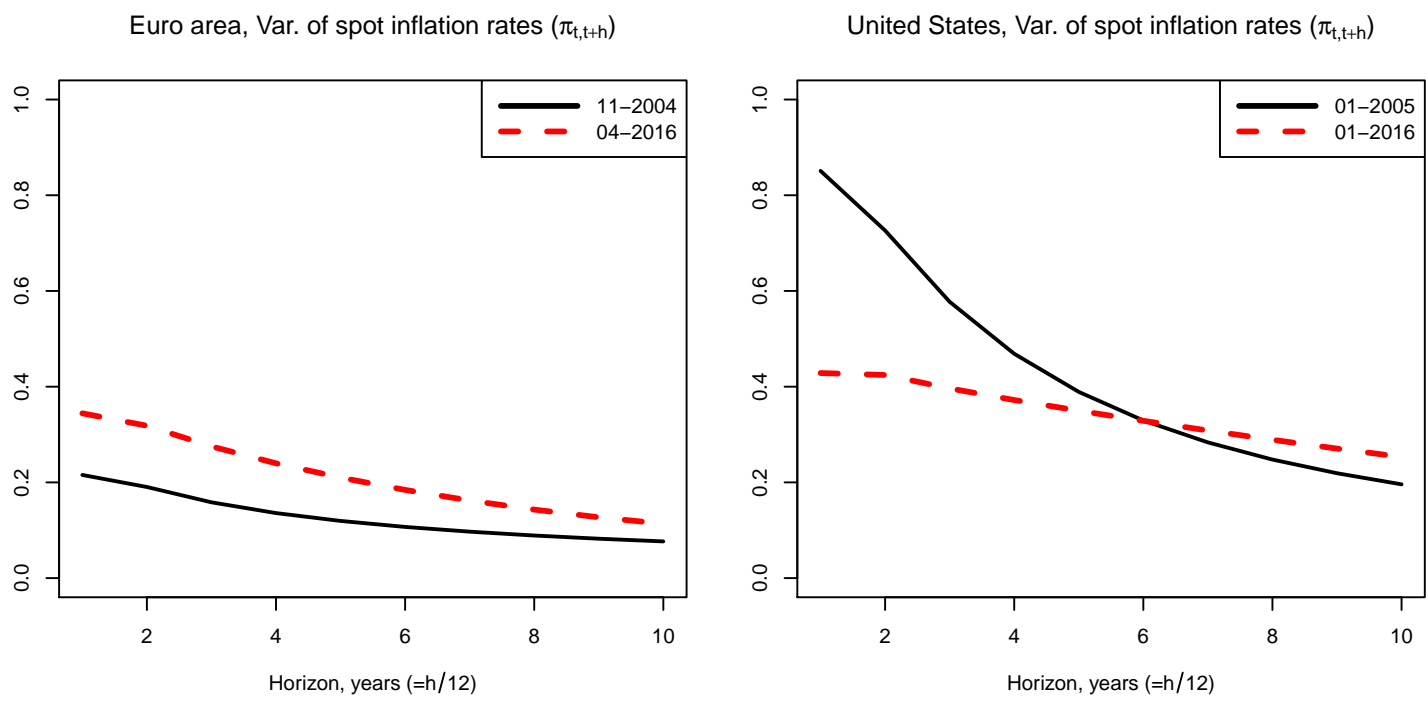

Euro area, Var. of forward inflation rates $\left(\pi_{\mathrm{t}+\mathrm{h}-12, \mathrm{t}+\mathrm{h}}\right)$

United States, Var. of forward inflation rates $\left(\pi_{\mathrm{t}+\mathrm{h}-12, \mathrm{t}+\mathrm{h}}\right)$
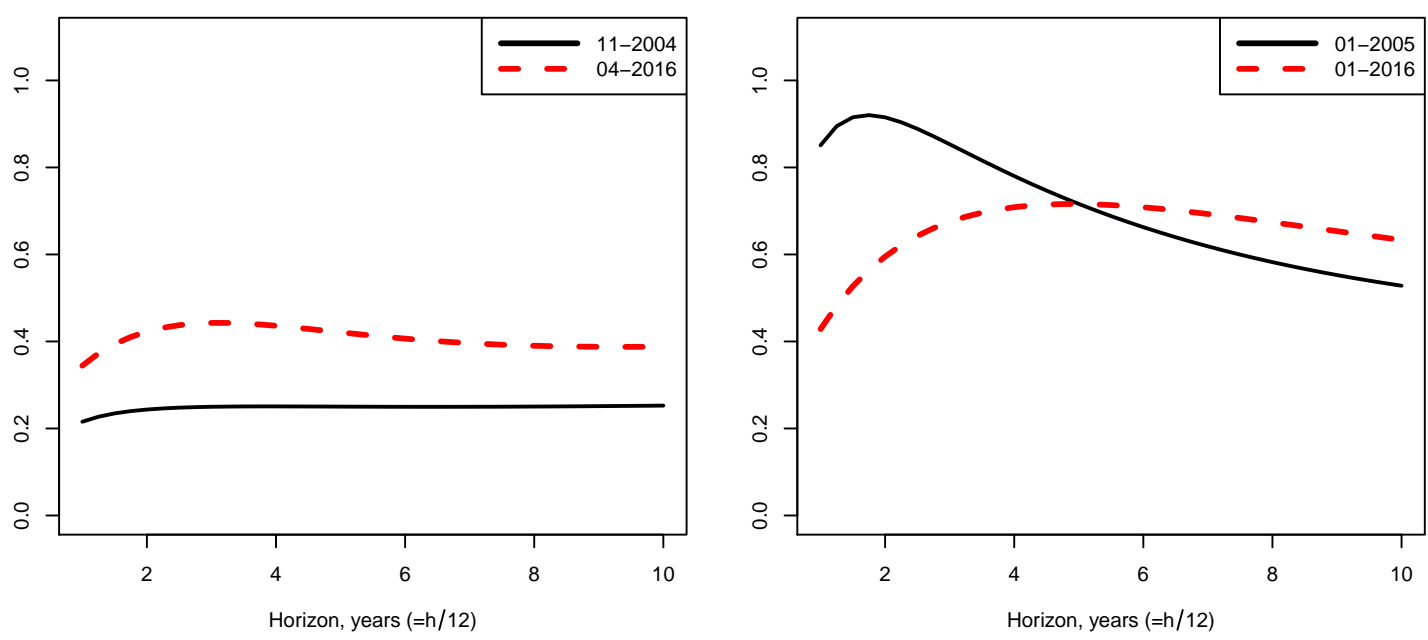

This figure displays the term structure of model-implied variances of the model-implied expected spot and forward inflation rates, which are plotted in Figure 4. The top two panels display the variances (or, inflation uncertainty) of the annualized average spot rates up to a horizon of 10 years in the euro area and the United States. The bottom two panels display the variances of the one-year rates $h$ periods ahead. 
Figure 6: Option-based and model-implied probabilities of low inflation

Euro area - Proba. of an inflation lower than $0 \%$

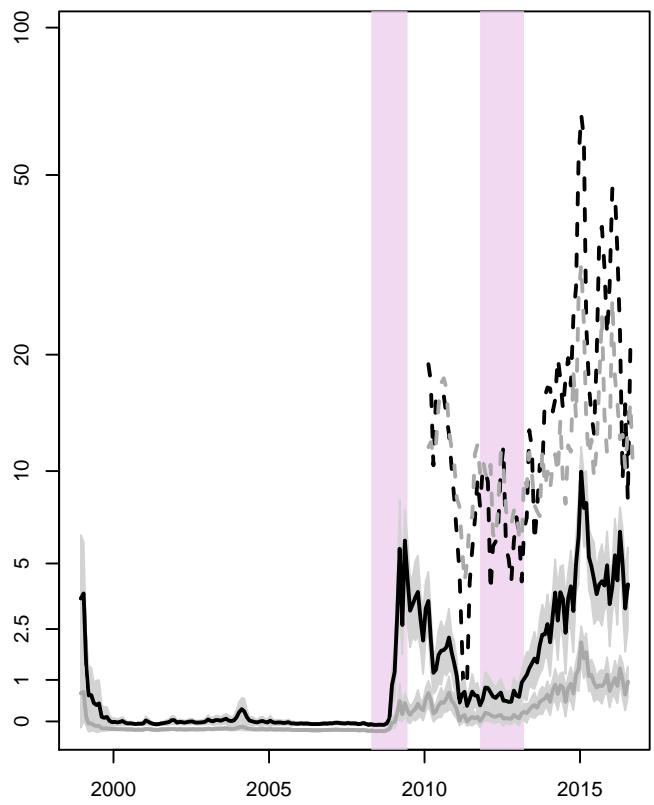

Euro area - Proba. of an inflation lower than $1 \%$

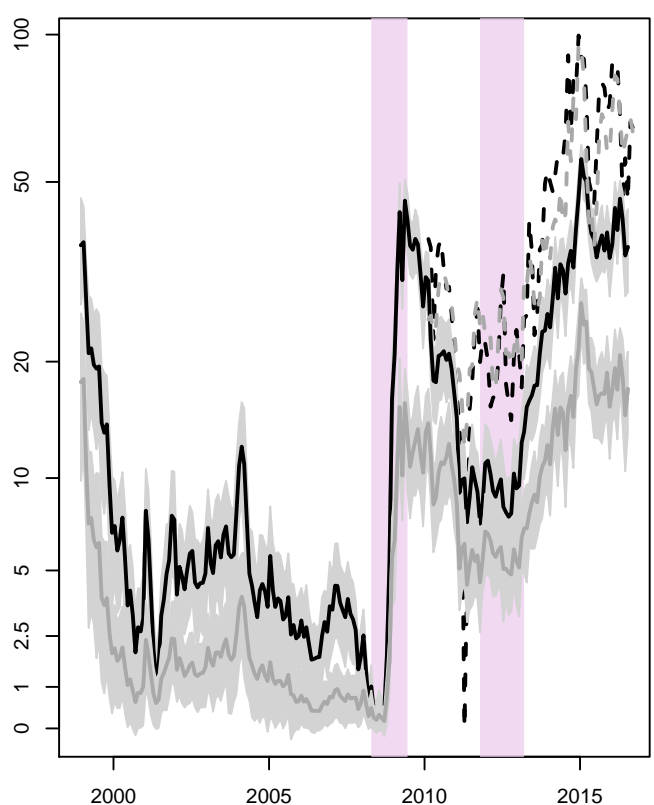

United States - Proba. of an inflation lower than $0 \%$

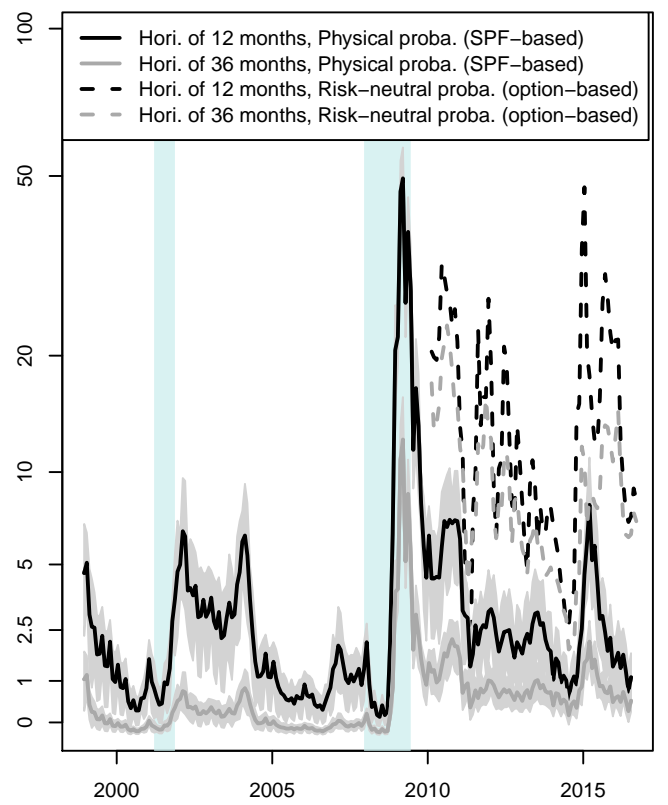

United States - Proba. of an inflation lower than $1 \%$

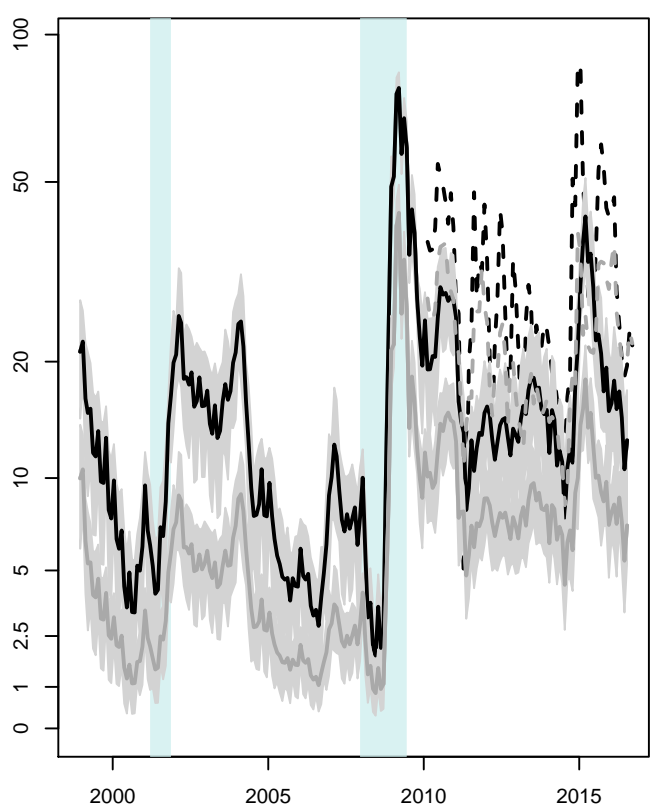

This figure compares model-implied deflation probabilities (top charts) and probabilities of inflation falling below 1 percent (bottom charts) in both economies to their risk-neutral counterparts. Formally, these probabilities are of the form $\mathbb{P}\left(\pi_{t, t+h}^{(i)}<\zeta \mid \underline{X_{t}}\right)$, with $h=12$ and 36 months and with $\zeta=0 \%$ and $1 \%$. The risk-neutral probabilities are based on inflation derivatives, namely zero-coupon inflation swaps and inflation floors. For the physical probabilities (solid lines), the grey-shaded areas corresponds to $95 \%$ confidence bands reflecting the uncertainty pertaining to the smoothing algorithm employed to estimate the state-vector $X_{t}$. 
Figure 7: Expected joint movements of euro-area and U.S. inflation rates
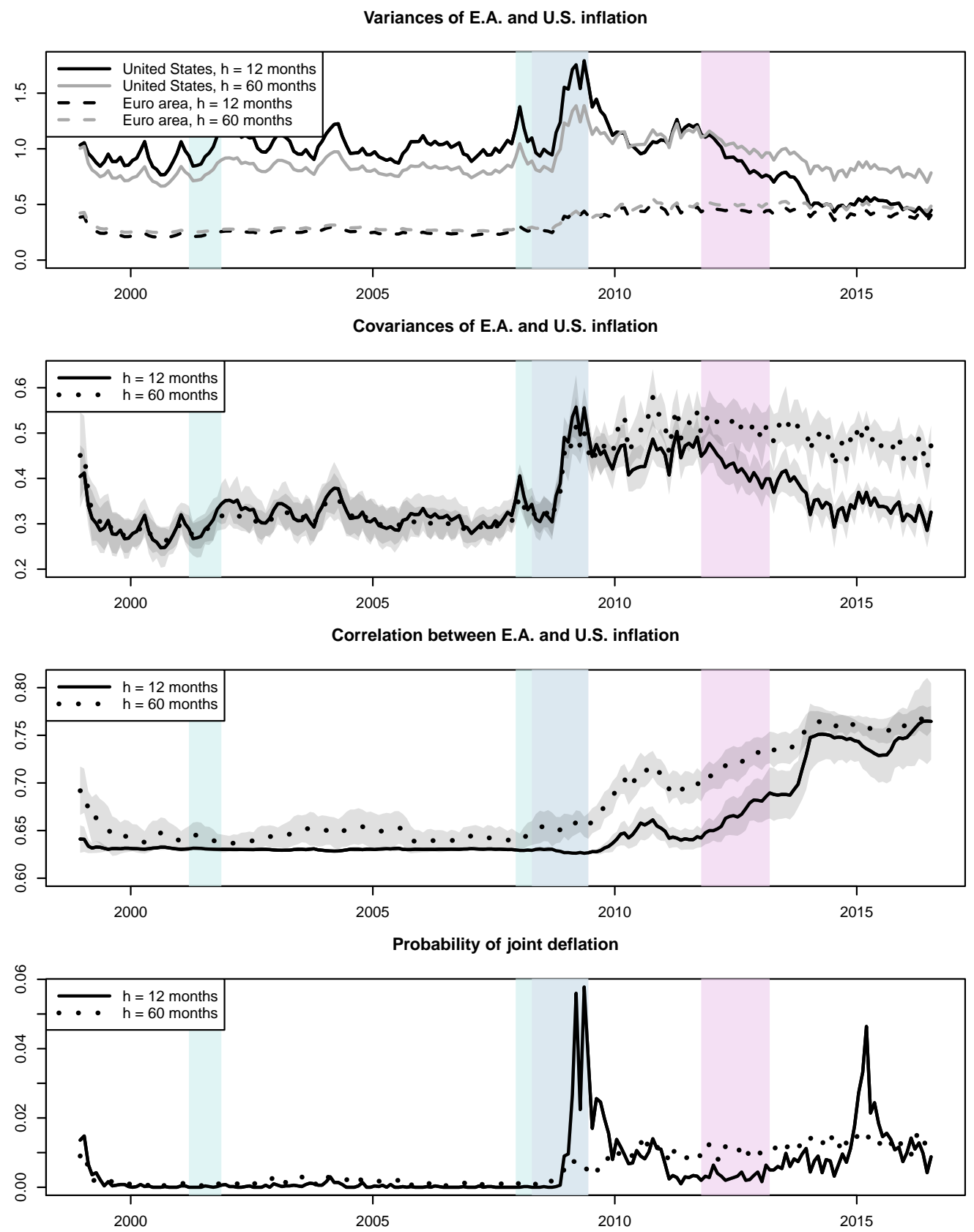

The top three panels display the U.S. and euro-area conditional variances, covariances and correlations of inflation rates for $h=12$ and $h=60$ months ahead. The bottom panel shows the joint probabilities of deflation, i.e. $\mathbb{P}\left(\pi_{t+h-12, t+h}^{(E . A .)} \leq 0, \pi_{t+h-12, t+h}^{(U . S .)} \leq 0 \mid \underline{X_{t}}\right)$ for the same horizons. For all panels, we consider conditional moments of $\pi_{t+h-12, t+h}^{(i)}$ conditional on $\underline{X_{t}}$. 
Figure 8: Measure of the anchoring of inflation expectations

Euro area - Proba. that inflation in [1.5\%,2.5\%]

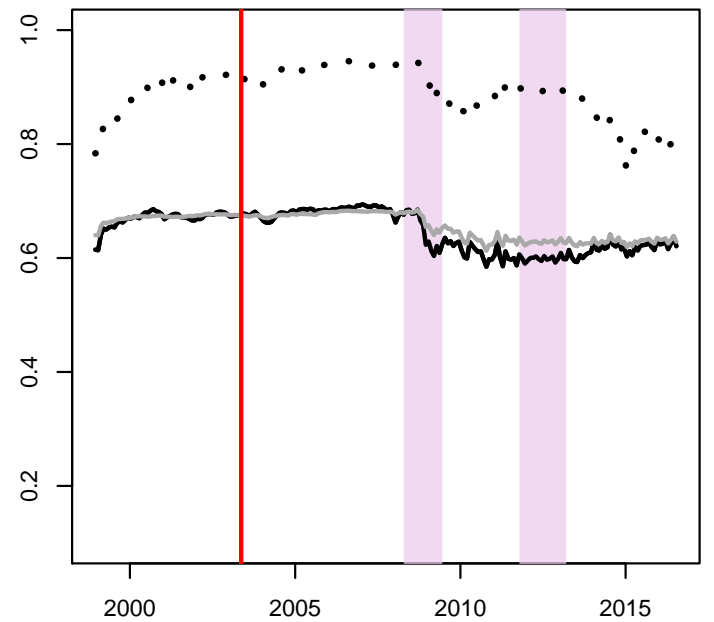

Euro area - Proba. that inflation in $[1 \%, 3 \%]$

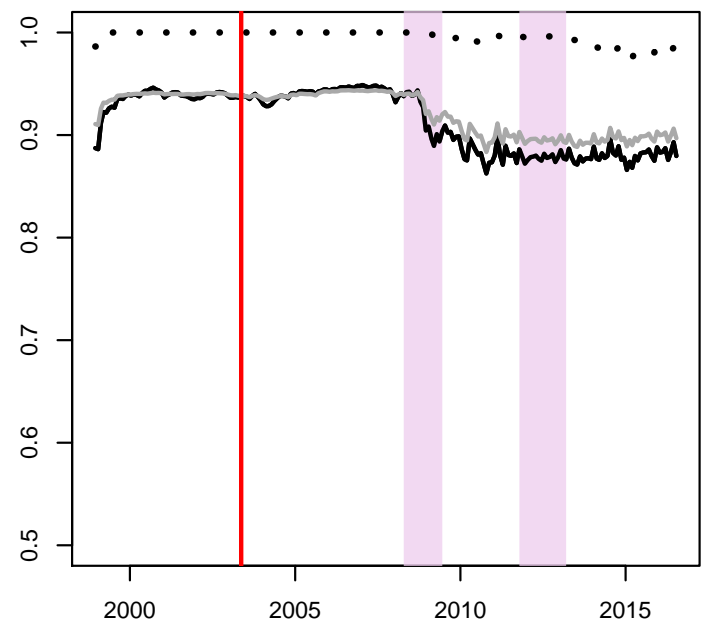

United States - Proba. that inflation in [1.5\%,2.5\%]

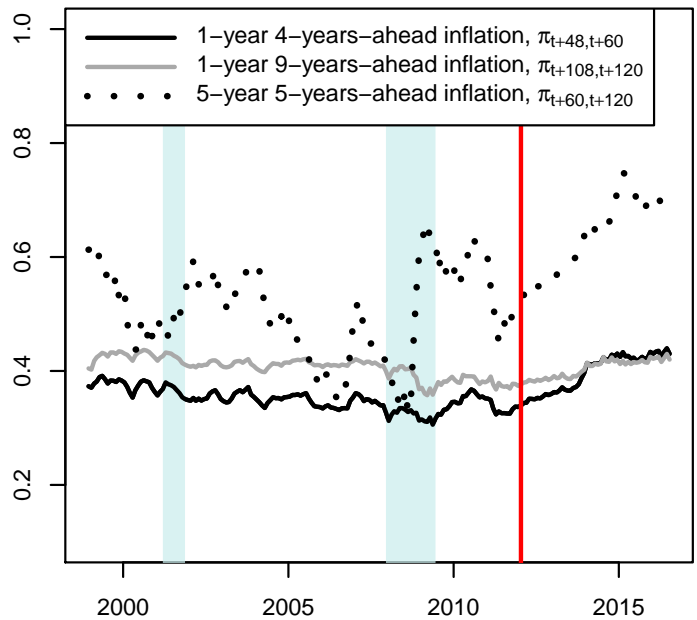

United States - Proba. that inflation in [1\%,3\%]

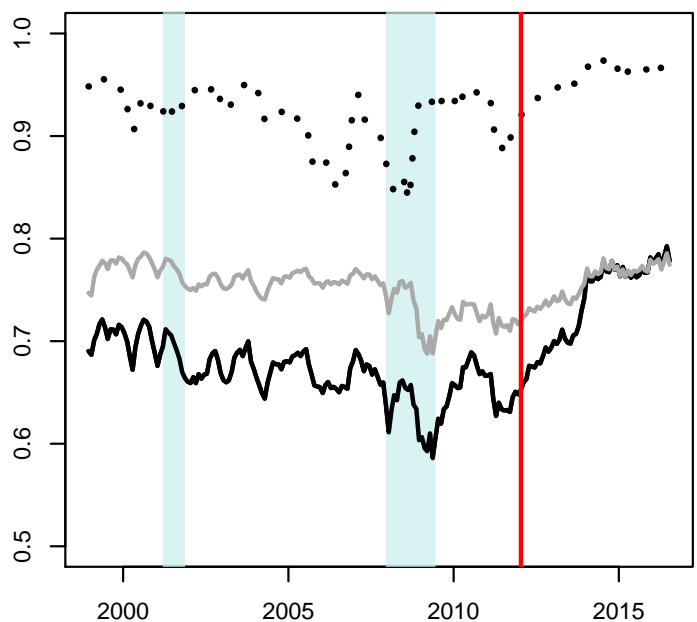

This figure displays probabilities that future inflation rates will fall in the two intervals: $I_{1}=$ $[1.5 \%, 2.5 \%]$ (upper plots) and $I_{2}=[1 \%, 3 \%]$ (lower plots). Formally, for an interval $I_{j}, j \in\{1,2\}$, the charts the time series of the conditional probabilities $\mathbb{P}\left(\pi_{t+h-m, t+h}^{(i)} \in I_{j} \mid \underline{X_{t}}\right)$ (h denotes the horizon, $m$ is the tenor). On each plot, three time series are plotted, they respectively correspond to $\{h=60, m=12\},\{h=120, m=12\}$ and $\{h=120, m=60\}$. The red vertical lines indicate the months when the ECB and the Federal Reserve announced their inflation objectives, in May 2003 and in January 2012, respectively. 